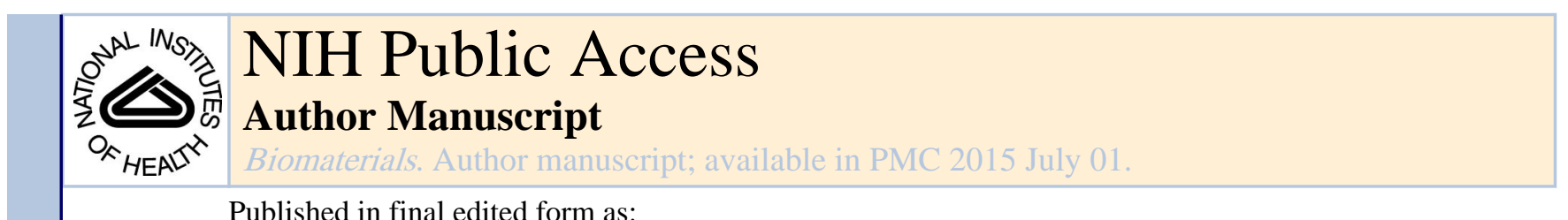

Published in final edited form as:

Biomaterials. 2014 July ; 35(23): 6026-6036. doi:10.1016/j.biomaterials.2014.04.015.

\title{
Tetraspecific Ligand for Tumor-Targeted Delivery of Nanomaterials
}

\author{
Dongwook Kim ${ }^{\dagger, \ddagger}$, Adam D. Friedman ${ }^{\dagger, \ddagger}$, and Rihe Liu ${ }^{\dagger, \ddagger}$, \\ tDivision of Chemical Biology and Medicinal Chemistry, UNC Eshelman School of Pharmacy, \\ University of North Carolina, Chapel Hill, North Carolina 27599-7568, U.S.A \\ ‡Carolina Center for Genome Sciences, University of North Carolina, Chapel Hill, North Carolina \\ 27599-7264, U.S.A
}

\section{Abstract}

The polygenetic nature of most cancers emphasizes the necessity of cancer therapies that target multiple essential signaling pathways. However, there is a significant paucity of targeting ligands with multi-specificities for targeted delivery of biomaterials. To address this unmet need, we generated a tetraspecific targeting ligand that recognizes four different cancer biomarkers, including VEGFR2, $a_{\mathrm{v}} \beta_{3}$ integrin, EGFR, and HER2 receptors, which have been implicated in numerous malignant tumors. The tetraspecific targeting ligand was constructed by sequentially connecting four targeting ligand subunits via flexible linkers, yielding a fusion protein that can be highly expressed in E. coli and readily purified to near homogeneity. Surface Plasmon Resonance (SPR), Bio-Layer Interferometry (BLI) studies and extensive cellular binding analyses indicated that all the targeting ligand subunits in the tetraspecific fusion protein recognized their target receptors proximately to the corresponding monospecific ligands. The resulting tetraspecific targeting ligand was applied for the delivery of nanomaterials such as gold nanoparticles (AuNPs) for targeted hyperthermic killing of various cancer cell lines with biomarkers of interest expressed. We demonstrate that the tetraspecific ligand can be facilely introduced on the surface of AuNPs and efficient target-dependent killing of cancer cells can be achieved only when the AuNPs are conjugated with the tetraspecific ligand. Significantly, the tetraspecific ligand simultaneously interacts with more than one receptors, such as EGFR and HER2 receptors, when they are expressed on the surface of the same cell, as demonstrated by in vitro binding assays and cell binding analyses. Our results demonstrate that the tetraspecific ligand, through multivalency and synergistic binding, can be readily used to generate various 'smart' biomaterials with greatly broadened tumor targeting range for simultaneous targeting of multiple signaling pathways on many different cancer types.

(C) 2014 Elsevier Ltd. All rights reserved.

*CORRESPONDING AUTHOR FOOTNOTE: Division of Chemical Biology and Medicinal Chemistry, UNC Eshelman School of Pharmacy, University of North Carolina, Chapel Hill, North Carolina 27599-7568 and Carolina Center for Genome Sciences, University of North Carolina, Chapel Hill, North Carolina 27599-7264, rliu@email.unc.edu, Telephone: 919-843-3635, Fax number: 919-966-0204

Publisher's Disclaimer: This is a PDF file of an unedited manuscript that has been accepted for publication. As a service to our customers we are providing this early version of the manuscript. The manuscript will undergo copyediting, typesetting, and review of the resulting proof before it is published in its final citable form. Please note that during the production process errors may be discovered which could affect the content, and all legal disclaimers that apply to the journal pertain. 


\section{Keywords}

Multispecificity; tetraspecific; targeting ligand; antibody mimic; multiple signaling pathways; AuNPs; targeted nanomaterials; synergistic binding; hyperthermia cancer therapy; near IR

\section{Introduction}

A major challenge in cancer nanotechnology is how to selectively deliver nanomaterials to diseased tissues while simultaneously minimizing their nonspecific accumulation on normal cells. Targeting ligands play a vital role in the targeted delivery of nanoparticles to the tumor sites [1,2]. However, there is a significant paucity of targeting ligands that are suitable for targeted delivery of nanomaterials, and therefore an urgent unmet need to develop targeting molecules that confer 'smartness' to nanoparticles [3,4].

Successful targeting of cancer cells with high specificity is, however, a complicated and daunting task. Different cancers are presumably different diseases with dissimilar expression profiles of cell surface biomarkers. Even for the same malignant tumor such as breast cancer, the HER2-positive rate is only $20-30 \%$, indicating that majority of breast cancer patients cannot benefit from the effective anti-HER2 therapies such as trastuzumab or pertuzumab [5]. Recent progress in sequencing the whole cancer genomes reveals catalogs of all the mutations that are present in the cancerous tissues [6,7]. In the case of pancreatic cancer, for example, an average of 63 genetic alterations that define a core set of 12 cellular signaling pathways and processes are exclusive to the diseased PDAC (pancreatic ductal adenocarcinoma) cells [7]. Such polygenetic nature of most cancers clearly indicates that any effective cancer treatment should be based on targeting multiple essential signaling pathways, presumably by using a combination of targeted therapeutics.

An ideal approach to addressing the challenge is by integrating the ability of targeting multiple cell surface biomarkers onto a single molecule. Such multispecific targeting ligands could have expanded spectrum of cancer indication and improved therapeutic efficacies, in addition to potentially reduced drug resistance. It has been reported that simultaneous targeting EGFR and IGF-1R, two tumor-associated receptors on either the same or adjacent tumor cells, using a recombinant bispecific antibody, had enhanced antitumor activity [8]. The approach was also demonstrated by an engineered bispecific antibody against VEGF and HER2 that effectively inhibited the growth of both VEGF- and HER2-dependent tumors in animal models [9].

Currently, there is an urgent need to confer multispecificity to biomaterials for their targeted delivery to diseased tissues. The central barrier is to develop next generation targeting ligands with multispecificity that can be tuned and applied to different cancer types [10,11]. While it is a great achievement to engineer a monoclonal antibody to acquire multispecificity, the process is often limited [12], in addition to high manufacturing cost. In this study, we aimed to develop a targeting ligand with tetraspecificity capable of binding four cell surface biomarkers, namely, VEGFR2, $\alpha_{v} \beta_{3}$ integrin, EGFR, and HER2, which are of significant cancer targeting interest [13-16]. We evaluated the design of the tetraspecific targeting ligand and the maintenance of specific targeting features for each individual 
targeting subunit. We investigated the site-specific conjugation of the tetraspecific ligand to a nanomaterial (AuNPs), the effectiveness of ligand-directed hyperthermia therapy against cancer cells expressing different biomarkers, and the synergistic effects derived from the tetraspecificity.

\section{Materials and Methods}

\subsection{Construction of Tetraspecific Targeting Ligand}

The coding sequences for each monospecific ligand were used for assembly of the fusion

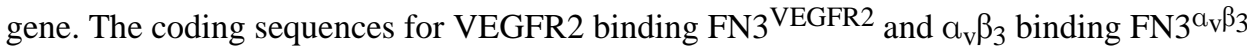
domains were synthesized by GenScript (Piscataway, NJ). The coding sequences for EGFRbinding $Z^{\mathrm{EGFR}}$ and HER2-binding $\mathrm{Z}^{\mathrm{HER} 2}$ domains were amplified from the genes coding heptameric ligands as we recently reported [17]. The amplified coding sequences were assembled to form a fusion gene by PCR using primers described in Supplemental Table 1. The final coding sequence for the tetraspecific ligand was ligated into pET28b between Nco $I$ and $X h o I$ sites and the accuracy was confirmed by DNA sequencing. The gene coding the tetraspecific ligand with a $\mathrm{C}$-terminal cysteine residue was constructed by PCR amplification using primers V9-5-23 and Tet-cys R as described in Supplemental Table 2.

\subsection{Expression and Purification of Tetraspecific Targeting Ligand}

The plasmid containing a monospecific or the tetraspecific ligand was transformed into E.coli BL21 (DE3) Rosetta cells. The positive clones were selected on LB plate containing kanamycin $(50 \mu \mathrm{g} / \mathrm{mL})$ and chloramphenicol $(34 \mu \mathrm{g} / \mathrm{mL})$. The single colony was picked and grown at $10 \mathrm{~mL} \mathrm{LB}$ overnight at $37^{\circ} \mathrm{C}$. The overnight $10 \mathrm{~mL}$ cell culture was added to $1 \mathrm{~L}$ of LB media containing kanamycin $(50 \mu \mathrm{g} / \mathrm{mL})$ and chloramphenicol $(34 \mu \mathrm{g} / \mathrm{mL})$. Cells were grown at $37^{\circ} \mathrm{C}$ until the O.D. 600 was between 0.5 to 1.0 , and $1 \mathrm{mM} \mathrm{IPTG}$ was added to induce expression at $22^{\circ} \mathrm{C}$ for $16 \mathrm{~h}$. After induction, the cells were spun down at $3,000 \times$ $\mathrm{g}$ for $10 \mathrm{~min}$ at $4{ }^{\circ} \mathrm{C}$, and the pellet was stored at $-20^{\circ} \mathrm{C}$ prior to further purification. To purify each monospecific or tetraspecific ligand, the cell pellet was resuspended in buffer $\mathrm{A}$ ( $25 \mathrm{mM}$ HEPES pH 7.4 and $50 \mathrm{mM} \mathrm{NaCl}$ ) and sonicated for $1 \mathrm{~min}$ for a total of 4 times. After cell lysis, the soluble fraction was recovered by centrifugation at $12,000 \times \mathrm{g}$ for $10 \mathrm{~min}$ at $4{ }^{\circ} \mathrm{C}$. The resulting soluble fraction was loaded onto a TALON metal affinity column (Clontech, Mountainview, CA) pre-equilibrated with buffer B (25 mM HEPES pH 7.4 and $300 \mathrm{mM} \mathrm{NaCl}$ ). An initial washing was performed by using buffer B followed by extensive washing with buffer $\mathrm{C}$ (buffer $\mathrm{B}$ and $20 \mathrm{mM}$ imidazole). The proteins of interest were eluted with buffer D (buffer B and $200 \mathrm{mM}$ imidazole). The quality of the purified proteins was checked with SDS-PAGE. The labeling of purified proteins by fluorescein isothiocyanate (FITC) (ACROS organics, Geels, Belgium) and Alexa Fluor 555 carboxylic acid, succinimidyl ester (Alexa 555) (Life technologies, Grand Island, NY) was performed according to the procedures as we published previously [17].

\subsection{Surface Plasmon Resonance (SPR) Analysis}

BIAcore 2000 (BIAcore AB, Uppsala, Sweden) was used for Surface Plasmon Resonance analysis of target-binding kinetics. Purified recombinant human VEGFR2 ECD-Fc, EGFR ECD-Fc and HER2 ECD-Fc were purchased from R\&D Systems (Minneapolis, MN). 
Human $\alpha_{v} \beta_{3}$ integrin was purchased from Millipore (Billerica, MA). Each receptor was diluted in a $10 \mathrm{mM}$ sodium acetate buffer at $\mathrm{pH} 5.0$ and immobilized on a CM5 sensor chip (GE Healthcare, Piscataway, NJ) to achieve about 2,500 resonance units through amine coupling according to the manufacturer's instructions. Various concentrations of monospecific and tetraspecific ligands were injected onto the flow cell in an HBS-P buffer (10 mM HEPES pH 7.4, $150 \mathrm{mM} \mathrm{NaCl}$, and $0.005 \%$ surfactant P20) at a flow rate of $20 \mu \mathrm{l} /$ min. The dissociation constants $\left(\mathrm{K}_{\mathrm{D}}\right)$ were calculated using BIA evaluation software by fitting data on one to one Langmuir binding model.

\subsection{Bio-Layer Interferometry (BLI) Analysis}

BLI analyses of the affinity of monospecific ligands, tetraspecific ligand or TetraS-AuNP biomaterial against each receptor were performed by using a fortéBIO Octet QK system. Assays were run at $30{ }^{\circ} \mathrm{C}$ on Greiner Bio One black 96-well microplates. Anti-hIgG Fc Capture (AHC) biosensors (Pall fortéBIO Corp, Menlo Park, CA) were used to immobilize the receptors of interest containing Fc, including human VEGFR2 ECD-Fc, EGFR ECD-Fc, HER2 ECD-Fc, and HER3 ECD-Fc. Ni-NTA biosensors (Pall fortéBIO Corp, Menlo Park, CA) were used to immobilize His-tagged targeting ligands for $a_{v} \beta_{3}$ binding analysis. All receptor ligand samples were prepared in an assay buffer $(1 \times \mathrm{PBS}, 0.002 \%$ Tween $20, \mathrm{pH}$ 7.4) and applied to a 96 well-microplate in column arrangement. Various concentrations of ligands were used to test the binding. Assays were run in triplicate via regeneration of the AHC biosensor with $10 \mathrm{mM}$ glycine, $\mathrm{pH}$ 2.5. All data were acquired in fortéBIO Data Acquisition 6.4 software. Analysis was performed in fortéBIO Data Analysis 6.4 software. Data processing was performed by averaging the reference biosensors, applying SavitzkyGolay Filtering, and fitting binding curves using global fitting and a 1:1 model.

\subsection{Cell Culture}

K562 ${ }^{\mathrm{a}_{\mathrm{v}} \beta_{3}}$ was a kind gift from Dr. S. Blystone (Upstate medical university, Syracuse, NY).

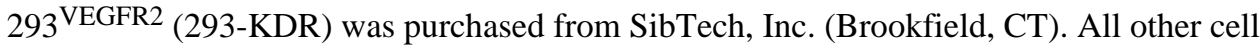
lines including wild type K562, wild type 293 HEK, EGFR-positive A431, HER2-positive SK-OV3, EGFR- and HER2-negative MCF7 cells were obtained from UNC Tissue Culture Facility. All cell lines were maintained by serial passage in each proper media containing $10 \%$ fetal bovine serum in $5 \% \mathrm{CO}_{2}$ incubator at $37^{\circ} \mathrm{C}$.

\subsection{Confocal Microscopy}

Each cell line (about $2 \times 10^{4}$ ) was seeded on coverslides and allowed to grow in a proper media for $16 \mathrm{~h}$. The resulting coverslips were washed with $1 \times$ PBS twice followed by incubation with various concentrations of FITC-labeled monospecific or tetraspecific ligand for $30 \mathrm{~min}$ at room temperature. The coverslips were washed with $1 \times$ PBS 3 times. The resulting samples were examined with a Zeiss LSM 510 confocal microscope at the UNC Microscopy Core.

\subsection{Circular Dichroism Spectroscopy}

Highly purified monospecific and tetraspecific ligands were prepared in a $10 \mathrm{mM}$ phosphate buffer (pH 7.5) and used for circular dichroism (CD) scanning with an AVIV model 202-01 
spectropolarimeter at the UNC Macromolecular Interaction Facility. To determine thermal stability, the CD spectra at $220 \mathrm{~nm}$ were measured from $25^{\circ} \mathrm{C}$ to $94{ }^{\circ} \mathrm{C}$, and the ramp was cool down to $25{ }^{\circ} \mathrm{C}$ followed by measuring the $\mathrm{CD}$ spectra at $220 \mathrm{~nm}$ again from $25^{\circ} \mathrm{C}$ to 94 ${ }^{\circ} \mathrm{C}$. The melting temperature $\left(\mathrm{T}_{\mathrm{m}}\right)$ was calculated as a temperature which has the midpoint $\mathrm{CD}$ spectra between the lowest and the highest CD spectra with reversible melting curve.

\subsection{Flow Cytometry and Cell-binding Analysis}

Cell binding of the monospecific and tetraspecific ligands was evaluated by using flow cytometry. Approximately $2 \times 10^{4}$ cells were grown on a 24 -well plate for $16 \mathrm{~h}$. After washing with $1 \times$ PBS the following day, cells were incubated with FITC-labeled monospecific or tetraspecific ligand for $30 \mathrm{~min}$ at room temperature, followed by washing with $1 \times$ PBS twice. The samples were analyzed by a flow cytometry (BD FACS Canto flow cytometry) and the data were analyzed by the Flow Jo system (Tree star, Inc. Ashland, OR).

\subsection{Conjugation of Tetraspecific Ligand with AuNPs}

$0.5 \mathrm{~mL}$ of AuNPs (30 nm gold nanoparticles, $0.01 \% \mathrm{Au}$, and $2 \times 10^{11}$ particles $/ \mathrm{mL}$, NANOCS, New York, NY) and $0.1 \mathrm{~mL}$ of tetraspecific ligand with a C-terminal cysteine (1 $\mu \mathrm{M}$ ) was incubated in $1 \times \mathrm{PBS}$ at $4{ }^{\circ} \mathrm{C}$ for $1 \mathrm{~h}$ under the protection of Argon gas, followed by saturating nanoparticle surfaces with $5 \mathrm{mM}$ of $2 \mathrm{kDa}$ mPEG-SH (NANOCS, New York, NY) (1: 200 volumetric ratio) at $4{ }^{\circ} \mathrm{C}$ for $4 \mathrm{~h}$. The solution was spun in a $300 \mathrm{~K}$ filtration column (Pall Corp, Port Washington, NY) at 12,000 rpm for $20 \mathrm{~min}$ to remove unreacted ligand and mPEG. The resulting TetraS-AuNP biomaterial was resuspended in $0.2 \mathrm{~mL}$ of $1 \times$ PBS. Concentration of TetraS-AuNP was estimated by the BCA assay.

\subsection{AuNPs-mediated Hyperthermia Treatment}

Each cell line (about $2 \times 10^{4}$ ) was seeded on coverslides and allowed to grow in a proper media for $16 \mathrm{~h}$. TetraS-AuNP biomaterial was incubated with each cell line at $37^{\circ} \mathrm{C}$ for 30 min. NIR irradiation $\left(800 \mathrm{~nm}, 1\right.$ watt) was performed for $20 \mathrm{~min}$ at $25^{\circ} \mathrm{C}$. The resulting cells were labeled by $1 \mu \mathrm{M}$ calcein AM (Life Technology, Carlsbad, CA) and $2 \mu \mathrm{M}$ ethidium homodimer-1 (Life Technology, Carlsbad, CA) at $25^{\circ} \mathrm{C}$ for $1 \mathrm{~h}$, for the detection of live and dead cells, respectively. The coverslides were washed with $1 \times$ PBS buffer 3 times. The resulting samples were examined with a Zeiss LSM 510 confocal microscope.

\subsection{Serum Stability}

Purified tetraspecific ligand $(5 \mu \mathrm{g})$ was incubated with $10 \%$ of mouse serum $(5 \mathrm{mg} / \mathrm{mL}$, Sigma Aldreich, MO) for 6 to $24 \mathrm{~h}$ at $37^{\circ} \mathrm{C}$. After incubation, 10 volume of buffer A was added and the remaining undigested ligand was purified from the reaction mixture using $\mathrm{Co}^{2+}$-NTA column. Samples were analyzed and quantified by using $12 \%$ SDS-PAGE.

\subsection{Cell Proliferation MTS Assay}

CellTiter96 Aqueous Non-Radioactive Cell Proliferation Assay kit from Promega (Madision, WI) was used for the MTS assay. Approximately $1 \times 10^{4}$ cells were seeded in each well of a 96-well plate and grown for $16 \mathrm{~h}$ at $37^{\circ} \mathrm{C}$. To examine the possible inhibition on cell proliferation, tetraspecific ligand was incubated with the cells for $48 \mathrm{~h}$ at $37^{\circ} \mathrm{C}$. 
Approximately $10 \mu \mathrm{M}$ Cis-platinum (II) diamine dichloride (Sigma-Aldreich Chemical Co, St Louis, MO) was used as a positive control. Approximately $20 \mu \mathrm{l}$ of MTS/PMS solution was added into each well followed by incubation for $4 \mathrm{~h}$ at $37^{\circ} \mathrm{C}$. The absorbance at $490 \mathrm{~nm}$ was recorded using an ELISA plate reader.

\section{Results}

\subsection{Design and Generation of Tetraspecific Targeting Ligand}

EGFR, HER2, VEGFR and $\alpha_{\mathrm{v}} \beta_{3}$ are four cell surface targets that have been clinically validated to have great therapeutic values [13-16]. Members of the EGFR or ErbB family are of great importance in a number of cancers due to their high potential to induce tumorigenesis if deregulated [14]. Under normal physiological conditions, ErbB receptors play essential roles in propagating signals for cell proliferation, differentiation, motility, and apoptosis [14]. Aberrant regulation of the ErbB/HER family and their ligands is a common occurrence in many human cancers, including breast, lung, colorectal, head and neck, and pancreatic cancers [18,19]. Co-overexpression of EGFR and HER2 has been found in some breast cancers and non-small cell lung cancer (NSCLC) [20,21]. Ligand-induced EGFR and HER2 heterodimerization activates downstream pathways that are essential for cell proliferation and survival, necessitating the targeting of both receptors simultaneously [14]. Tumor angiogenesis is common in most, if not all, solid tumors, and angiogenesis-related cell surface receptors are important anti-cancer targets [22]. It is now clear that disruption of angiogenesis represents a promising approach to the treatment of many types of cancers $[15,22]$. Signaling pathways mediated by $a_{v} \beta_{3}$ and VEGF/VEGFR are critical for tumor angiogenesis [23]. VEGF is upregulated in many human cancers and promotes endothelialcell proliferation, migration and survival, expression of adhesion molecules, and potently induces increased vascular permeability [15]. Integrin $\alpha_{v} \beta_{3}$ is a multi-functional glycoprotein that plays a major role in tumor angiogenesis and metastasis [22]. Both VEGFR and $\alpha_{\mathrm{v}} \beta_{3}$ have been shown to be overexpressed on the surface of proliferating endothelial cells during tumor angiogenesis [23]. Significantly, there is a mutually beneficial relationship between VEGFR 2 and integrin $\alpha_{v} \beta_{3}$ since each receptor is able to promote activation of its counterpart via the formation of a heterodimer [23,24]. Such VEGFR2 and $a_{v} \beta_{3}$ transactivation allows cells to regulate cellular activities, such as cell migration, survival, and differentiation [23]. Therefore, targeting $\alpha_{\mathrm{v}} \beta_{3}$ and VEGFR represents a promising anti-angiogenic approach to the treatment of multiple types of solid tumors [24]. Furthermore, increasing evidence suggests a link between the EGFR/HER2 and VEGFR/ $a_{v} \beta_{3}$ pathways, including a crosstalk between integrin $\alpha_{v} \beta_{3}$ and EGFR receptors [23-25]. A single targeting ligand that can bind and recognize all four targets holds the promise of targeting many different cancer types. In particular, nanoparticles conjugated with such tetraspecific targeting ligand could be used for the targeted delivery to diseased tissues with very different biomarker expression profiles and therefore have greatly expanded cancer indications.

To develop a tetraspecific targeting ligand that can be used for targeting nanoparticles to a wide variety of cancers, we used the single domain antibody mimics based on the type III domain of fibronectin (FN3) and the three-helix bundle $\mathrm{Z}$ domain $[26,27]$. The FN3 domain 
has a sandwich immunoglobulin-like scaffold and ligand-binding surface loops structurally analogous to the three CDRs of the immunoglobulin $\mathrm{V}_{\mathrm{H}}$ domain [26]. FN3-based single domain antibody mimics have several unique properties that make them ideal ligands for targeting nanoparticles. These features include the small size $(<10 \mathrm{kDa})$, high thermostability $\left(\mathrm{T}_{\mathrm{m}} \sim 90^{\circ} \mathrm{C}\right.$ ), lack of disulfide bonds, low cost (highly expressed in E. coli), and low immunogenicity (derived from highly abundant extracellular fibronectin) [26]. The three-helix bundle $\mathrm{Z}$ domain derived from Staphylococcal aureus surface protein A is another scaffold that is widely used for the development of affinity molecules through directed evolution strategy [27]. Despite its bacterial origin and thus potential immunogenicity, $\mathrm{Z}$ domain is also highly stable $\left(\mathrm{T}_{\mathrm{m}} \sim 78^{\circ} \mathrm{C}\right)$ and lack of disulfide bonds, and can be expressed with high yields in bacteria [27]. In addition, both FN3 and Z domains are highly modular, making it possible to easily introduce desired specificities by using tandem fusion approach.

To develop the tetraspecific targeting ligand, we chose VEGFR2-binding FN3 ${ }^{\text {VEGFR2 }}, a_{\mathrm{v}} \beta_{3^{-}}$ binding FN $3^{a_{v} \beta_{3}}$ for targeting VEGFR2 and $a_{v} \beta_{3}$, and EGFR-binding $Z^{E G F R}$ and HER2binding $\mathrm{Z}^{\mathrm{HER} 2}$ for targeting EGFR and HER2, respectively [28-31]. Gly/Ser and Pro/Gln rich flexible linkers were used to connect each targeting moiety as shown in Figure 1A and Supplemental Table 2. It has been reported that these linkers are flexible and do not interfere with the function of each domain in multidomain proteins [32]. The DNA sequences that code for different moieties, including FN3 ${ }^{\mathrm{VEGFR} 2}, \mathrm{FN} 3^{\mathrm{a}_{ } \mathrm{B}_{3}}, \mathrm{Z}^{\mathrm{EGFR}}, \mathrm{Z}^{\mathrm{HER} 2}$ and the flexible linkers between each two targeting moieties, were optimized for codon usage in E. coli. The resulting cDNA fusion gene was assembled and cloned into expression vector $\mathrm{pET}-28 \mathrm{~b}$ for overexpression in E. coli. A $6 \times$ His tag, introduced onto the C-terminus of the fusion protein, permitted facile purification via immobilized metal affinity column chromatography (IMAC) (Figure 1A). If necessary, the $6 \times$ His tag can be removed by TEV-mediated cleavage at a site engineered downstream of the last targeting domain. The expressions of tetraspecific ligand and each of the monospecific ligand in $E$. coli were induced by the addition of $1 \mathrm{mM}$ IPTG. As shown in Figure 1B, the tetraspecific ligand and each of the monospecific ligands were highly expressed as soluble proteins and purified to near homogeneity through a $\mathrm{Co}^{2+}$-NTA column (Figure 1B). No degradation of the tetraspecific ligand was observed, indicating that the generation strategy for tetraspecific targeting ligand was successful.

\subsection{Analysis of Target Binding Affinity and Specificity}

To examine whether the tetraspecific targeting ligand maintains recognition of each target of interest, we compared the target-binding properties of the tetraspecific ligand with that of the four monospecific ligands via Surface Plasmon Resonance (SPR) and Bio-Layer Interferometry (BLI) (Table 1). For assays using SPR, the extracellular domain (ECD) of EGFR, HER2, or VEGFR2 was immobilized on a CM5 sensor chip via amine coupling and the target-binding parameters were measured by injecting the monospecific or tetraspecific targeting ligands into the flow cell at various concentrations. As shown in Supplemental Figure 1 and Table 1, tetraspecific ligand maintained binding to EGFR, HER2, and VEGFR2 with affinities around $17 \mathrm{nM}, 15 \mathrm{nM}$, and $1.4 \mathrm{nM}$, compared to $2.6 \mathrm{nM}, 0.9 \mathrm{nM}$, and $0.5 \mathrm{nM}$ for monospecific $\mathrm{Z}^{\mathrm{EGFR}}, \mathrm{Z}^{\mathrm{HER} 2}$, and FN3 ${ }^{\mathrm{VEGFR} 2}$, respectively. In general, the 
binding affinity of the tetraspecific ligand for each target was relatively weaker than that of the corresponding monospecific ligand due to faster dissociation of tetraspecific ligand from the receptors. For example, $\mathrm{k}_{\text {off }}$ of monospecific $\mathrm{Z}^{\mathrm{EGFR}}\left(2.6 \pm 0.3 \times 10^{-7} \mathrm{~s}^{-1}\right)$ is 20 times slower than that of tetraspecific ligand $\left(5.2 \pm 1.2 \times 10^{-6} \mathrm{~s}^{-1}\right)$ against EGFR (Table 1). The faster dissociation of tetraspecific ligand might be caused from the presence of the other binding moieties. In the case of $\alpha_{\mathrm{v}} \beta_{3}$, we found that $\alpha_{\mathrm{v}} \beta_{3}$ immobilized on CM5 sensor chip was not functional, presumably due to the modification of residues involved in binding with the ligand during covalent immobilization of $\alpha_{v} \beta_{3}$, resulting in failure to measure the $\alpha_{v} \beta_{3^{-}}$ binding using SPR. To address the problem, we used the Bio-Layer Interferometry (BLI) that allows for the measurement of target-binding through analysis of the interference pattern of white light reflected from a surface layer of immobilized protein on the biosensor tip, compared with that from an internal reference surface layer $[33,34]$. Thus, monospecific $\mathrm{FN}{ }^{\mathrm{a}_{\mathrm{v}} \mathrm{\beta}_{3}}$ and tetraspecific ligand were immobilized on the anti-His Octet biosensor through the C-terminal $6 \times$ His tag, and free $\alpha_{v} \beta_{3}$ integrin was included in the solution at different concentrations for binding analysis using a fortéBio Octet QK system. As shown in Supplemental Figure 1D, the tetraspecific ligand bound to $\alpha_{\mathrm{v}} \beta_{3}$ with an affinity around 73 $\mathrm{nM}$, which is 2.3-fold weaker compared with that of the monospecific FN3 ${ }^{\mathrm{av} \beta 3}(\sim 31 \mathrm{nM})$, suggesting the integration of $\mathrm{FN}^{\mathrm{av} \beta 3}$ into a tetraspecific fusion does not much interfere with its target-binding features. It is worth mentioning that the reduction of target-binding affinity of the two $\mathrm{Z}$ domain-based ligands was more remarkable, with 6.5 -fold and 16-fold decrease in binding with EGFR and HER2, whereas only 2.8-fold and 2.3-fold decrease in FN3 domain-based ligands for VEGFR2 and $\alpha_{v} \beta_{3}$, respectively (Table 1). These results suggest that FN3-based monobodies appear to be more stable and less structurally disturbed when present in a fusion protein, consistent with its higher stability and biologically active tandem oligomeric form in the highly abundant fibronectin present in numerous mammals. Altogether, these experiments demonstrated that the tetraspecific ligand bound to all four target receptors in vitro and retained the desired tetraspecificity as designed.

\subsection{Analysis of Cellular Binding Features}

The successful binding of purified receptors by a targeting ligand under in vitro conditions does not necessarily mean it can recognize and target the native form of a receptor on the surface of cancer cells. To address this concern, we first examined the functionality of the tetraspecific ligand via confocal cell binding assays by incubating FITC-labeled tetraspecific ligand or the four monospecific ligands using cell lines with and without the expression of each receptor. Specifically, A431 and SK-OV3 cells were well characterized for their high level of expression on EGFR and HER2, respectively, and were used as positive cell lines for the binding of EGFR and HER2. For $\alpha_{v} \beta_{3}$ and VEGFR2, we used engineered K562 ${ }^{a_{v}} \beta_{3}$ and $293^{\text {VEGFR } 2}$ as positive cell lines on which the gene of $\alpha_{v} \beta_{3}$ or VEGFR 2 was stably transfected, respectively $[29,35]$. To study the background and nonspecific binding of the targeting ligands, cell lines that are known to express no or very low levels of the receptors of interest were used as negative controls. These include MCF7 cells that express low level of both EGFR and HER2, wild-type K562 cells negative for $\alpha_{\mathrm{v}} \beta_{3}$, and wild-type 293 cells negative for VEGFR2. As illustrated in Figure 2, $100 \mathrm{nM}$ of FITC-labeled monospecific ligands respectively recognized each positive cell line (A431, SKOV3, K562 ${ }^{\mathrm{a} v \mathrm{\beta} 3}$, and $293^{\text {VEGFR2 }}$ ), whereas their bindings to the corresponding negative cell lines (MCF7, K562, 
and 293) were either not detectable or close to the background. Just like each of the monospecific ligands, the tetraspecific ligand recognized all the positive cell lines, but not the negative control cell lines, indicating it combines the four desired specificities within one fusion molecule and interacts well with all four receptors that are present as the biologically active conformations on the surface of cancer cells. To quantitatively compare the receptor-dependent cell-binding, we used flow cytometry to estimate the cell-binding affinities. As shown in Table 2, the binding specificities of tetraspecific ligand against cell lines expressing VEGFR2, $a_{v} \beta_{3}$, EGFR, and HER2, respectively, were all well retained, with the affinities decreased only 1.2- to 2.5-fold compared to the corresponding monospecific ligands. The results from combined confocal and flow cytometry studies clearly indicated that the cell binding of the tetraspecific ligand was highly receptordependent and the binding affinities were only slightly diminished compared to the corresponding monospecific ligands, indicating that the desired tetraspecificity was combined in the fusion ligand for in vivo cellular applications.

\subsection{Analysis of Toxicity and Stability}

Most nanoparticles have complicated and often not well-characterized surface properties which can result in denaturation of protein-based targeting ligands whose correct folding relies on maintaining a hydrophobic core. The chemical conjugation of nanoparticles with a targeting ligand often involves harsh reaction conditions that disrupt its targeting feature. In addition, the abundant proteases under physiological conditions can quickly degrade the targeting moieties on the surface of nanoparticles, unless they are highly resistant to proteolysis. Therefore, targeting ligands with high thermal stability and protease resistance are greatly desirable. To address these problems, the thermal stability of purified tetraspecific and monospecific ligands was determined by circular dichroism (CD) analysis. It was found that all four monospecific ligands were stable for up to $80{ }^{\circ} \mathrm{C}$, with a $\mathrm{T}_{\mathrm{m}}$ for FN3 ${ }^{\text {VEGFR2 }}, \mathrm{FN}^{\mathrm{a}_{\mathrm{v}} \beta_{3}}, \mathrm{Z}^{\mathrm{EGFR}}$, and $\mathrm{Z}^{\mathrm{HER} 2}$ at approximately $61{ }^{\circ} \mathrm{C}, 80{ }^{\circ} \mathrm{C}, 61^{\circ} \mathrm{C}$, and $63{ }^{\circ} \mathrm{C}$, respectively (Table 3). Surprisingly, the tetraspecific ligand also showed a reversible melting curve from $25^{\circ} \mathrm{C}$ to $94{ }^{\circ} \mathrm{C}$, and yielded a $\mathrm{T}_{\mathrm{m}}$ of approximately $60^{\circ} \mathrm{C}$, despite the presence of three flexible linker regions. These results suggest that the high stability exhibited by the individual monospecific moieties against heat induced denaturation was well maintained in the tetraspecific fusion protein. We further assessed the stability of the tetraspecific ligand in serum by incubating purified tetraspecific ligand with mouse serum for 6,12 and $24 \mathrm{~h}$, respectively. As illustrated in Figure 3, tetraspecific ligand proved to be remarkably stable in mouse serum after up to $24 \mathrm{~h}$ incubation at $37{ }^{\circ} \mathrm{C}$ (Figure 3 ).

Any useful targeting ligands should be non-toxic themselves prior to their application on the delivery of nanoparticles. The toxicity of the tetraspecific ligand was examined by the cell proliferation assays using four different cell lines that overexpress EGFR, HER2, $\alpha_{\mathrm{v}} \beta_{3}$, and VEGFR2 respectively. As shown in Figure 4, no apparent cell growth inhibition was observed on any of these cell lines, when the ligand concentration was used up to $1 \mu \mathrm{M}$. This result indicates that tetraspecific ligand is non-toxic and safe to use, at least on the cell lines we have tested. 


\subsection{Characterization of Tetraspecific-AuNP Biomaterials}

To apply the tetraspecific ligand in targeting cancer cells expressing different biomarkers, we conjugated the tetraspecific ligand with gold nanoparticles (AuNPs) and applied the resultant biomaterial for killing various cancer cells in a highly specific biomarkerdependent manner via light-mediated hyperthermia treatment [36-40]. To minimize the interference of the targeting feature by the NP surface immobilization, we took advantage of the lack of any cysteine residues on the tetraspecific ligand and genetically engineered the only cysteine at the $\mathrm{C}$-terminus of the fusion protein. This only thiol group allows for oriented, site-specific immobilization of tetraspecific ligand on the surface of AuNPs through robust $\mathrm{Au}-\mathrm{S}$ bond formation. To increase the stability and minimize nonspecific binding or uptake of AuNPs by cancer cells, the unoccupied surface of targeted AuNPs were further saturated with thiol PEG (mPEG-SH, $2 \mathrm{kDa}$ ) (Figure 5A). We systematically examined the target-binding feature of the resultant tetraspecific ligand-AuNP (TetraSAuNP) biomaterial by using BLI-based Octet. This was readily achieved by measuring the binding between various concentrations of TetraS-AuNP biomaterial in solution with the $\mathrm{Fc}$ fusion of a target receptor (i.e. EGFR-Fc, HER2-Fc, or VEGFR2-Fc) immobilized on the anti-human Fc capture (AHC) Octet biosensors. Due to the lack of a tagged $a_{v} \beta_{3}$ protein, the binding with $a_{v} \beta_{3}$ integrin was not included. As shown in Table 4 , the binding affinities of the TetraS-AuNP biomaterial to EGFR, HER2 and VEGFR2 were estimated at approximately $54 \mathrm{nM}, 5.2 \mathrm{nM}$, and $3.9 \mathrm{nM}$, respectively, which were decreased from 2- to 5fold compared with unconjugated tetraspecific ligand. Again, it appears that the reduction of the target-binding affinity of $\mathrm{Z}$ domain-based moieties was more remarkable than that of FN3 domain-based moieties, consistent with our hypothesis that FN3 domain is more resistant to structurally disturbing environment. Despite this minor reduction, the resulting TetraS-AuNP biomaterial still possesses low to medium nanomolar target-binding affinities and retains the desired multispecificity very well.

\subsection{Hyperthermia Treatment}

To demonstrate that the tetraspecific ligand can be used to broaden tumor targeting range of nanomaterials with improved targeting efficiency, we used the TetraS-AuNP biomaterial for biomarker-dependent killing of four different cancer cell lines, namely A431, SKOV3, U87MG, and $293^{\text {VEGFR2 }}$ cells, which overexpress or express EGFR, HER2, $a_{v} \beta_{3}$, and VEGFR2, respectively, through hyperthermia treatment. Briefly, $100 \mathrm{nM}$ TetraS-AuNP biomaterial was first incubated with each cell line at $37{ }^{\circ} \mathrm{C}$ for $30 \mathrm{~min}$ to promote ligand-receptor binding and/or receptor-mediated endocytosis. After extensive washing to remove TetraSAuNP biomaterial that was not internalized or weakly attached to cancer cells, the cells were irradiated for $20 \mathrm{~min}$ by using a near IR (NIR) laser at $800 \mathrm{~nm}$ and 1 watt [41]. To assess cell viability, calcein AM and ethidium homodimer (EthD-1) were added one hour postirradiation, for the detection of live cells and dead cells, respectively [41]. As shown in Figure $5 \mathrm{~B}-\mathrm{C}$, all four cell lines were viable upon the NIR irradiation in the presence or absence of the PEGylated AuNPs, indicating that NIR irradiation was not harmful to the cancer cells, and the PEGylated AuNPs were neither nonspecifically attached nor uptaken by these cancer cells, at least under the conditions we applied. When the AuNPs were targeted with the tetraspecific ligand, significant cell death (95\%) was observed for A431, SKOV3, and $293^{\text {VEGFR2 }}$ cells, upon irradiation using NIR laser for $20 \mathrm{~min}$ (Figures 5B and 
C), whereas cells outside of the irradiation range maintained near complete viability (Supplemental Figure 2). For U87MG cells, the percentage of cell death was approximately $20 \%$ (Figure 5B), consistent with the low expression level of $a_{v} \beta_{3}$ on the surface of this cell line [42]. These results strongly suggest that the tetraspecific ligand can be used to effectively targeting AuNPs for hyperthermia-mediated cell killing of different cancer cell lines in a highly specific biomarker-dependent manner.

\subsection{Analysis of Synergistic Binding to EGFR and HER2}

As we have demonstrated, the tetraspecific ligand retains specific binding against all four targets and should presumably show synergistic avidity effect when more than two receptors are present on the cancer cell surface with relatively similar abundances. However, it is challenging to examine such synergistic effect because the expression levels of different biomarkers on cancer cells are often highly biased and it is difficult to find well characterized cancer cell lines that have two biomarkers (i.e., EGFR and HER2) expressed at proximate levels. To quantitatively address the possible synergistic effect, we first used an artificial system by immobilizing EGFR and HER2 on the surface of Octet biosensor at different ratios, which allows us to measure the binding affinities when EGFR and HER2 are present at different concentrations and ratios. To precisely tune the ratio between EGFR and HER2 on the surface, we used anti-human Fc capture biosensor that could capture the Fc portion of EGFR extracellular domain (ECD)-Fc and HER2 ECD-Fc with equal strength and therefore result in surface with EGFR and HER2 immobilized at pre-determined ratios. As shown in Table 5, when EGFR or HER2 was immobilized alone, no additive effect on binding affinity was detected. Significantly, a dramatic synergistic binding effect (more than 1,500-fold and 10,000-fold increase for HER2 and EGFR binding, respectively) was observed when EGFR and HER2 were immobilized at 1:1 molar ratio, a condition that presumably maximizes the avidity binding effect. When either EGFR or HER2 was coimmobilized with HER3 ECD-Fc, no such additive effect was observed, consistent with the absence of HER3-binding moiety in the tetraspecific ligand. This result also suggested that the binding of tetraspecific ligand with EGFR/HER2 could be much tighter than that of monospecific ligands. This result also suggested that the binding of tetraspecific ligand with EGFR/HER2 could be much tighter compared to monospecific ligands. To investigate this possibility, we performed a competitive binding assay of monospecific ligands with tetraspecific ligand using a biosensor with both EGFR and HER2 immobilized. The experiment was designed to first bind tetraspecific ligand to biosensors with both receptors immobilized, followed by a competitive binding with either buffer (Figure 6A, no competition) or a high concentration mixture of EGFR and HER2 monospecific ligands as competitors (Figure 6B). As illustrated in Figure 6, the target-binding of monospecific ligands on EGFR/HER2 was completely abrogated by the pre-bound tetraspecific ligand (Figure 6B), suggesting that tetraspecific ligand binds both EGFR and HER2 receptors simultaneously and with binding strength much higher than each of the monospecific ligands.

To examine the synergistic effect in cell-based assays, the cell line used for test must express at least two of the target receptors at relatively similar levels. We chose prostate cancer cell line LNCaP because these cells appear to express EGFR and HER2 at levels that 
are not very different [43]. As illustrated in Figure 7A, both EGFR- and HER2-binding monospecific ligands and tetraspecific ligand (all labeled with Alexa 555) bound to LNCaP cells when the concentrations were used at $200 \mathrm{nM}$. We postulated that the binding of fluorescently-labeled tetraspecific ligand to LNCaP cells should be abolished by a large excess of unlabeled same ligand. However, if the binding involves two different receptors, the synergistic avidity effect will make the tetraspecific ligand bind more tightly, an interaction that is difficult to disrupt by a large excess of monospecific EGFR- and HER2binding ligands, even when both are present. Indeed, incubation of $200 \mathrm{nM}$ Alexa 555labeled tetraspecific ligand with LNCaP cells in the presence of 10-fold molar excess $(2 \mu \mathrm{M})$ of unlabeled tetraspecific ligand yielded no detectable cell binding compared to background cellular autofluorescence (Figure 7B). However, the binding of Alexa 555-labeled tetraspecific ligand was maintained at up to $90 \%$ fluorescent intensity compared to the binding of tetraspecific ligand alone (Figure 7A) when incubated with LNCaP cells in the presence of 10-fold molar excess $(2 \mu \mathrm{M})$ of both unlabeled monospecific EGFR- and HER2binding ligands (Figure 7C).

\section{Discussion}

It is widely believed that combination anti-cancer therapies that simultaneously target multiple signaling pathways essential for tumorigenesis and metastasis could increase therapeutic efficacy and limit the development of drug resistance. One promising approach to addressing the challenge is by conferring multiple specificities to nanomaterials, which hold the great potential of being applied for simultaneous targeting of multiple signaling pathways on many different cancer types. Targeting ligands based on large and complex structures (i.e., monoclonal antibodies) are difficult to engineer to achieve desirable targeting features, including low cost, high stability, multispecificity, and site-specific conjugation, that are ideal for conferring smartness to nanoparticles [1-3]. Considerable attention has been paid to the utility of small protein domains as a source of engineered affinity molecules. Targeting ligands based on monomeric small protein domains with high solubility, stability, and minimal aggregation tendency are ideal for oriented and sitespecific conjugation with nanoparticles that often possess complex and denaturing surfaces. Furthermore, small targeting ligands with simple but stable structures allow for accommodation of greater number of targeting moieties on the nanoparticle surface. In this study, a tetraspecific targeting ligand was developed by genetically fusing four monospecific targeting ligands in tandem against EGFR, HER2, $\alpha_{\mathrm{v}} \beta_{3}$, and VEGFR2, respectively, via flexible and tunable linkers. In general, the binding affinity of the tetraspecific ligand against each target receptor was slightly decreased compared to the corresponding monospecific ligand. We attribute this to the complex structure of the tetraspecific ligand and possible inter-domain hindrance that might result in minor structural disturbance and reduced accessibility by the target receptors. Despite these minor reductions in binding affinity, our analyses demonstrate the persistence of biomarker-dependent binding of tetraspecific ligand to four different cell lines overexpressing each targeting receptor. It is possible to further tune the lengths and positions of the flexible linkers to minimize the affinity reduction. In principle, each targeting moiety in the tetraspecific ligand is readily tunable and replaceable by other desired targeting moiety. In addition, other modular domains can be integrated, 
including more targeting moieties or domains with biological functions such as cell membrane penetration and siRNA-binding. In the clinic, however, immunogenicity has complicated attempts to assemble different functional domains into a single multispecific ligand due to non-human origin of many engineered targeting ligands. Because FN3 domains are commonly found in many extracellular human proteins and therefore less immunogenic, engineered targeting ligands based on FN3 domains with human origin could be developed to address this issue [26]. Our tetraspecific ligand currently features a mixture of $\mathrm{Z}$ domain and FN3 domain-based monospecific ligands, but the plasticity inherent in our design would allow replacement of the bacterial $\mathrm{Z}$ domain-based ligands with human FN3 domain-based variants. We are currently engineering all FN3-based multispecific targeting ligands to several other cancer biomarkers.

It has been a major unmet need to overcome the acquired drug resistance in a wide variety of cancer cells. The maintenance of multispecificity, thermal and serum stability, and low cellular toxicity of tetraspecific ligand makes it a highly valuable reagent for targeting nanoparticles to kill cancer cells regardless of their genetic background. AuNPs are ideal for tetraspecific functionalization because of their facile synthesis, biocompatibility, nontoxicity, utility in imaging, and potential application in therapy due to the well-documented NIR-induced hyperthermia effect [2, 38,39]. We demonstrated that tetraspecificity was readily conferred to AuNPs, and the resulting AuNP biomaterial can be used to induce effective cell death through NIR irradiation in a highly specific biomarker-dependent manner (Figure 5). Therefore, the tetraspecific ligand developed in this work provides a facile and robust approach to targeting gold nanoparticles for hyperthermic treatment of various cancers with different biomarkers and drug resistant properties. It should be noted that the conjugation of tetraspecific ligands onto AuNPs did not improve target-binding compared to free tetraspecific ligand. We suspect that the expected avidity effect could be compromised in many targeted biomaterials due to the presence of multiple un-optimized components on the surface of biomaterials. In AuNPs, for example, the introduction of PEG, which is generally used to make nanoparticles biocompatible and well dispersed in physiological conditions, could affect multivalency and avidity. Ideally, the targeting ligands should be conjugated at the end of PEG molecules to minimize the potential for interference from PEG. It appears that the presence of the PEG layer on AuNPs does not affect targetbinding affinity and specificity of the tetraspecific ligand. We attribute this to the introduction of long flexible linkers on the tetraspecific ligand and the use of low molecular weight ( $2 \mathrm{kDa}$ ) PEG with a shorter length than high molecular weight PEGs. It is also possible that the density of PEG on the surface of AuNPs is not high, making tetraspecific ligands still accessible by their receptors. It is of great interest to compare the monospecific ligand to tetraspecific ligand in the AuNP studies. However, the binding affinity of each monomeric targeting ligand is stronger than that of the corresponding one on the tetraspecific ligand (Table 1). This makes the comparison between monospecificallytargeted and tetraspecifically-targeted AuNPs difficult. AuNPs are limited, however, in that they are not biodegradable and NIR has limited penetration depth when used in the clinic [44]. Other nanomaterials, such as polymeric nanoparticles, liposomes, and inorganic nanoparticles can be easily functionalized with ligands containing a single $\mathrm{C}$-terminal cysteine, thereby expanding the repertoire of the tetraspecific ligand in nanoparticle 
applications $[1,3,4]$. The combination of the tetraspecific ligand described here with different nanomaterials allows for the generation of a wide variety of 'smart' biomaterials that can be used to target multiple types of cancer cells with improved targeting efficiency.

Our experiments indicate a greatly empowering synergistic effect between the tetraspecific ligand and both EGFR/HER2 receptors (Figures 6, 7, and Table 5). This is consistent with the report by Ekerljung and co-workers showing that a bispecific affibody against EGFR and HER2 had up to 30 -fold enhanced binding affinity upon simultaneous binding to both receptors [45]. We demonstrated that the tetraspecific ligand possessed desirable synergistic receptor-binding effect to a much greater extent. Upon in vitro binding with surface immobilized EGFR/HER2 at a 1:1 molar ratio, the target-binding affinity of the tetraspecific ligand increased approximately 1,500-fold and 10,000-fold for HER2 and EGFR, respectively (Table 5). Cell-based competition assays confirmed that the tetraspecific ligand bound EGFR and HER2 on LNCaP cells synergistically, rather than additively, making the binding not disruptable by a 10 -fold molar excess of a mixture of monospecific ligands (Figure 7). Due to the highly varied expression level and internalization rate of different cell surface receptors, and the non-equilibrium environment under physiological conditions, it is challenging to investigate the effect of the high-affinity tetraspecific ligand on receptormediated endocytosis. We speculate that, overall, tetraspecific ligand endocytosis is more likely to be determined by those receptor(s) with relatively higher abundances. Depending on the endocytotic properties of these receptors, the endocytosis of the nanomaterials targeted by the tetraspecific ligand could be compromised, unaffected, or potentially enhanced. The availability of this tetraspecific ligand will facilitate future studies of this question. Once tetraspecific binds EGFR and HER2, it is possible to induce heterodimerization between EGFR and HER2, but it is unlikely to generate biologically active form of the heterodimer, which requires significant ligand-mediated conformational change. Indeed we did not observe any cell proliferation or toxicity effect induced by tetraspecific ligand (Figure 4).

\section{Conclusion}

In summary, a simple targeting ligand with tetraspecificity was successfully generated and applied for the delivery of nanomaterials for targeted hyperthermia treatment of cancer cells expressing different biomarkers. Synergistic binding effects and the effectiveness of the TetraS-AuNP biomaterial indicate the great translational potential of this technology in the facile generation of 'smart' nanomaterials with greatly broadened tumor targeting range and efficiency.

\section{Supplementary Material}

Refer to Web version on PubMed Central for supplementary material.

\section{Acknowledgments}

This work was supported by National Institutes of Health grant nos. CA151652 and CA157738 to R.L. 


\section{References}

1. Davis ME, Chen Z, Shin DM. Nanoparticle therapeutics: an emerging treatment modality for cancer. Nature Reviews Drug Discovery. 2008; 7:771-781.

2. Vigderman L, Zubarev ER. Therapeutic platforms based on gold nanoparticles and their covalent conjugates with drug molecules. Adv Drug Del Reviews. 2013; 65:663-676.

3. Friedman AD, Claypool SE, Liu R. The smart targeting of nanoparticle. Curr Pharm Des. 2013; 19:6315-6329. [PubMed: 23470005]

4. Wang AZ, Langer R, Farokhzad OC. Nanoparticle delivery of cancer drugs. Annu Rev Med. 2012; 63:185-198. [PubMed: 21888516]

5. Baselga J, Cortes J, Kim SB, Im SA, Hegg R, Im YH, Roman L, Pedrini JL, et al. Pertuzumab plus trastuzumab plus docetaxel for metastatic breast cancer. The New Eng Jour of Med. 2012; 366:109119.

6. Vogelstein B, Papadopoulos N, Velculescu VE, Zhou S, Diaz LA, Kinzler KW. Cancer genome landscapes. Science. 2013; 339:1546-1558. [PubMed: 23539594]

7. Jones S, Zhang X, Parsons DW, Kinzler KW, et al. Core signaling pathways in human pancreatic cancers revealed by global genomic analysis. Science. 2008; 321:1801-1806. [PubMed: 18772397]

8. Dong J, Sereno A, Aivazian D, Langley E, Miller BR, Snyder WB, Chan E, Cantele M, et al. A stable IgG like bispecific antibody targeting the epidemal growth factor and the type I insulin-like growth factor receptor demonstrates superior anti-tumor activity. MAbs. 2011; 3:273-288. [PubMed: 21393993]

9. Bostrom J, Yu SF, Kan D, Appleton BA, Lee CV, Billeci K, Man W, Peale F, et al. Variants of the antibody herceptin that interact with HER2 and VEGF at the antigen binding site. Science. 2009; 323:1610-1614. [PubMed: 19299620]

10. Sliwkowski MX, Mellman I. Antibody therapeutics in cancer. Science. 2013; 341:1192-1198. [PubMed: 24031011]

11. Kontermann RE. Dual targeting strategies with bispecific antibodies. MAbs. 2012; 4:182-197. [PubMed: 22453100]

12. LaFleur DW, Abramyan DA, Kanakara P, Smith RG, Shah RR, Wang G, Yao XT, Kankanala S, Boyd E, Zaritskay L. Monoclonal antibody therapeutics with up to five specificities: functional enhancement through fusion of target-specific peptides. MAbs. 2013; 5:2, 208-218.

13. Gossage L, Eisen T. Targeting multiple kinase pathways: a change in paradigm. Clinical Cancer Research. 2010; 16(7):1973-1978. [PubMed: 20215532]

14. Tebbutt N, Pedersen MW, Johns TG. Targeting the ERBB family in cancer: couples therapy. Nature Reviews Cancer. 2013; 13:663-673.

15. Youssoufian H, Hicklin DJ, Rowinsky EK. Review: monoclonal antibodies to the vascular endothelial growth factor receptor-2 in cancer therapy. Clinical Cancer Research. 2007; 13:55445548.

16. Curzio R, Gian CA. Vascular integrins: therapeutic and imaging targets of tumor angiogenesis. Angiogenesis Inhibition. 2010:83-101.

17. Kim D, Yan Y, Valencia CA, Liu R. Heptameric targeting ligands against EGFR and HER2 with high stability and avidity. PLoS One. 2012; 7:e43077. [PubMed: 22912791]

18. Kruser TJ, Wheeler DL. Mechanisms of Resistance to HER Family Targeting Antibodies. Exp Cell Res. 2010; 316:1083-1100. [PubMed: 20064507]

19. Geuna E, Milani A, Redana S, Rossi V, Valabrega G, Aglietta M, Montemurro F. Hitting multiple targets in HER2-positive breast cancer: Proof of principle or therapeutic opportunity? Expert Opinion Pharmacother. 2011; 12(4):549-565.

20. Tsutsui S, Ohnom S, Murakami S, Kataoka A, Kinoshita J, Hachitanda Y. Prognostic value of the combination of epidermal growth factor and c-erB-2 in breast cancer. Surgery. 2003; 133:219 221. [PubMed: 12605184]

21. Hirsch FR, Varella-Garcia M, Cappuzzo F. Predictive value of EGFR and HER2 overexpression in advanced non-small-cell lung cancer. Oncogene. 2009; 28:S32-S37. [PubMed: 19680294] 
22. Robinson SD, Hodivala-Dilke KM. The role of $\beta 3$-integrins in tumor angiogenesis: context is everything. Curr Opin in Cell Biol. 2011; 23:630-637. [PubMed: 21565482]

23. Somanath PR, Malinin NL, Brzova TV. Cooperation between integrin aV $\beta 3$ and VEGFR2 in angiogenesis. Angiogenesis. 2009; 12:177-185. [PubMed: 19267251]

24. Ivaska J, Heino J. Interplay between cell adhesion and growth factor receptors: from the plasma membrane to the endosomes. Cell Tissue Res. 2010; 339:111-120. [PubMed: 19722108]

25. Poindessous V, Ouaret D, El Ouadriani K, Battistella A, Megalophonos VF, Kamsu-Kon N, Petitprez A, Escargueli AE, et al. EGFR- and VEGFR-targeted small molecule show synergistic activity in colorectal cancer models refractory to combinations of monoclonal antibodies. Clinical Cancer Research. 2011; 17(20):6522-6530. [PubMed: 21880790]

26. Lipovsek D. Adnectins: engineered target-binding protein therapeutics. Protein Eng Des \& Sel. $2011 ; 24: 3-9$.

27. Nord K, Gunneriusson E, Ringdahl J, Stahl S, Uhlen M, Nygren PA. Binding proteins selected from combinational libraries of an alpha-helical bacterial receptor domain. Nat Biotechnol. 1997:772-777. [PubMed: 9255793]

28. Getmanova EV, Chen Y, Bloom L, Gokemeijer J, Shamah S, Warikoo V, Wang J, Ling V, Sun L. Antagonists to human and mouse vascular endothelial growth factor receptor 2 generated by directed protein evolution in vitro. Chemistry and Biology. 2006; 13:549-556. [PubMed: 16720276]

29. Duan J, Wu J, Valencia CA, Liu R. Fibronectin type III domain based monobody with high avidity. Biochemistry. 2007:12656-12664. [PubMed: 17929945]

30. Friedman M, Orlova A, Johansson E, Eriksson TL, Holden-Guthenberg I, et al. Directed evolution to low nanomolar affinity of a tumor-targeting epidermal growth factor receptor binding affibody molecule. J Mol Biol. 2008; 376:1388-1402. [PubMed: 18207161]

31. Orlova A, Magnusson M, Eriksson TL, Nilsson M, Larsson B, et al. Tumor imaging using a picomolar affinity HER2 binding affibody molecule. Cancer Res. 2006; 66:4339-4348. [PubMed: 16618759]

32. Chen X, Zaro JL, Shen WC. Fusion protein linkers: property, design and functionality. Adv Drug Deliv Rev. 2013; 65:1357-69. [PubMed: 23026637]

33. Citartan M, Gopinath SCB, Tominaga J, Tang TH. Label-free methods of reporting biomolecular interactions by optical biosensors. Analyst. 2013; 138:3576-3592. [PubMed: 23646346]

34. Smith MC, Scaglione KM, Assimon VA, Patury S, Thompson AD, Dickey CA, Southworth DR, Paulson HL, et al. The E3 ubiquitin ligase CHIP and the molecular chaperone Hsc70 form a dynamic, tethered complex. Biochemistry. 2013; 52(32):5354-5364. [PubMed: 23865999]

35. Hotz B, Backer MV, Backer JM, Buhr HJ, Hotz HG. Specific targeting of tumor endothelial cells by a shiga-like toxin-vascular endothelial growth factor fusion protein as a novel treatment strategy for pancreatic cancer. Neoplasia. 2010; 12:797-806. [PubMed: 20927318]

36. Huff TB, Tong L, Zhao Y, Hansen MN, Cheng JX, Wei A. Hyperthermic effects of gold nanorods on tumor cells. Nanomedicine (Lond). 2007; 2:125-132. [PubMed: 17716198]

37. Huang X, El-Sayed IH, Qian W, El-Sayed MA. Cancer cell imaging and hotothermal therapy in the near-infrared region by using gold nanorods. J Am Chem Soc. 2006:2115-2120. [PubMed: 16464114]

38. West JL, Halas NJ. Engineered nanomaterials for biophotonics applications: Improving sensing, imaging, and therapeutics. Annu Rev Biomed Eng. 2003:285-292. [PubMed: 14527314]

39. Kennedy LC, Bickford LR, Lewinski NA, Coughlin AJ, Hu Y, Day ES, West JL, Drezek RA. A new era for cancer treatment: gold-nanoparticle-mediated thermal therapies. Small. 2011:169-183. [PubMed: 21213377]

40. Huang YF, Liu H, Xiong X, Chen Y, Tan W. Nanoparticle mediated IgE receptor aggregation and signaling in RBL mast cells. J Am Chem Soc. 2009:17328-17334. [PubMed: 19929020]

41. Day ES, Bickford LR, Slater JH, Riggall NS, Drezek RA, West JL. Antibody-conjugated gold-gold sulfide nanoparticles as multifunctional agents for imaging and therapy of breast cancer. Int Journal of Nanomedicine. 2010; 5:445-454.

42. Zhang X, Xiong Z, Wu Y, Cai W, Tseng JR, Gambhir SS, Chen X. Quantitative PET imaging of tumor integrin $a V \beta 3$ expression with ${ }^{18}$ F-FRGD2. The J Nuclear Med. 2006; 47:113-121. 
43. Rusnak DW, Alligood KJ, Mullin RJ, Spehar GM, Gilmer TM, et al. Assessment of epidermal growth factor receptor (EGFR, Erb1) and HER2 (ErbB2) protein expression levels and response to lapatinib (Tykerb, GW572016) in an expanded panel of human normal and tumour cell lines. Cell Prolif. 2007; 40:580-594. [PubMed: 17635524]

44. Almeida JPM, Figueroa ER, Drezek RA. Gold nanoparticle mediated cancer immunotherapy. Nanomedicine. 2013 Oct 5. pii: S1549-9634(13)00545-5. [Epub ahead of print]. 10.1016/j.nano. 2013.09.011

45. Ekerljung L, Wållberg H, Sohrabian A, Andersson K, Friedman M, et al. Generation and evaluation of bispecific affibody molecules for simultaneous targeting of EGFR and HER2. Bioconjug Chem. 2012; 23:1802-1811. [PubMed: 22882002] 


\section{Figure 1A}

\section{FN3 ${ }^{\text {VEGFR2 }}$ FN3 ${ }^{\alpha_{\mathrm{v}} \beta_{3}} \quad$ Z $^{\text {EGFR }} \quad$ Z $^{\text {HER2 }}$}

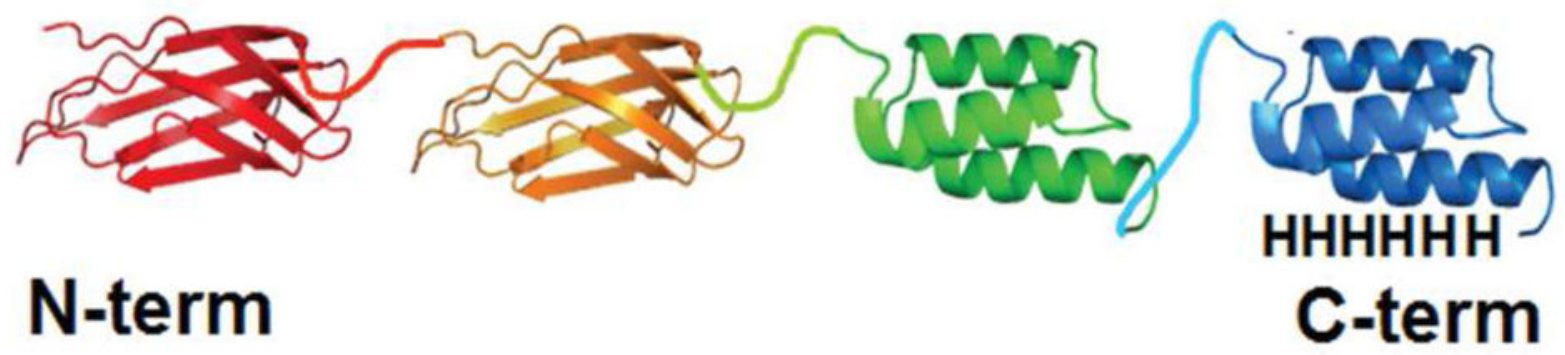

Figure 1B

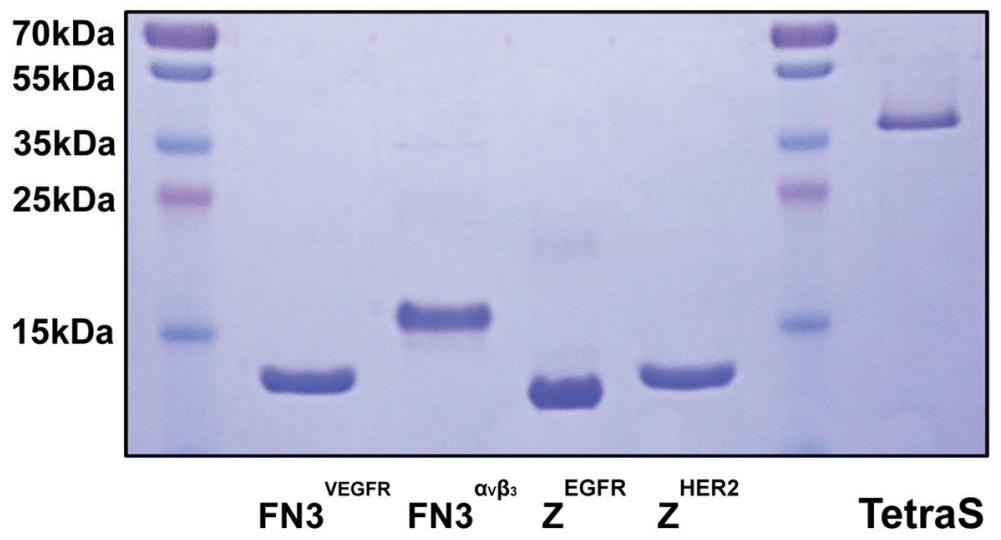

Figure 1.

Figure 1 A. Schematic Diagram and Design of the Tetraspecific Ligand

A tetraspecific ligand consists of four target binding moieties and three flexible hinge linkers. $6 \times$ His tag was engineered at the $\mathrm{C}$-terminus to facilitate affinity purification. Figure 1 B. Purification of Monospecific and Tetraspecific Ligands on SDS-PAGE. Each of the monospecific and tetraspecific ligands was purified by metal affinity column chromatography and separated on $12 \%$ SDS-PAGE for analysis. 
Figure 2A
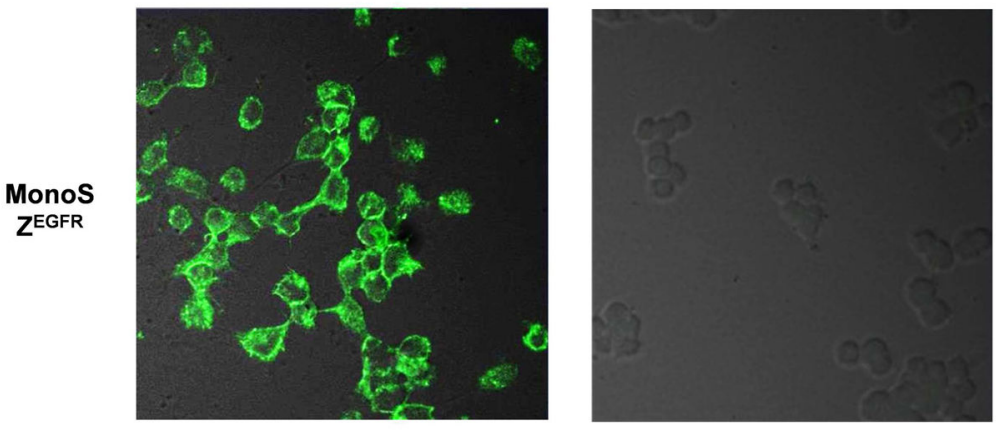

Tetras

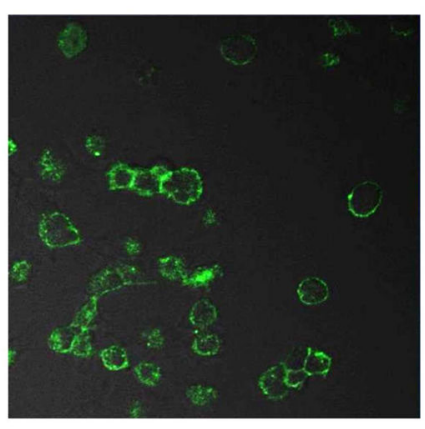

EGFR overexpressing A431 cells

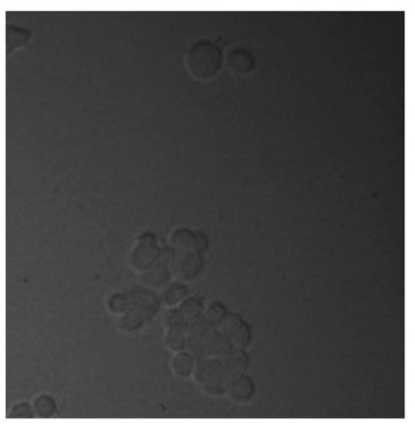

MCF7 cells 


\section{Figure 2B}

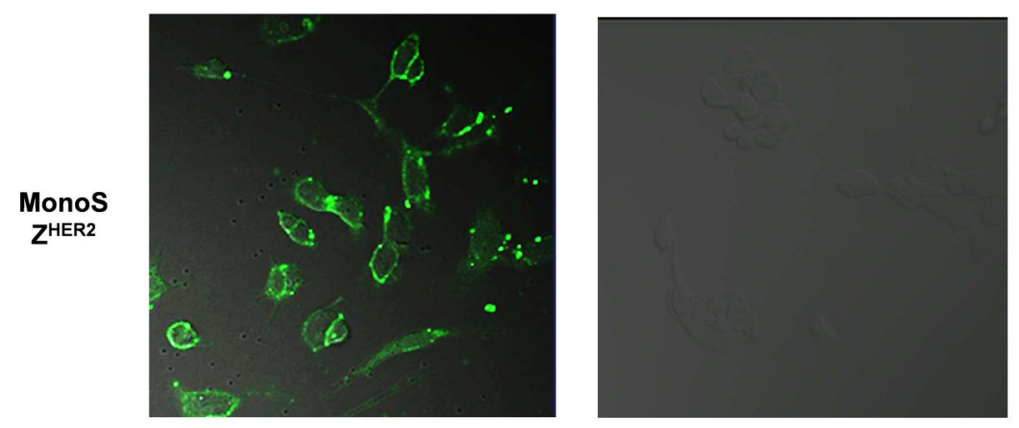

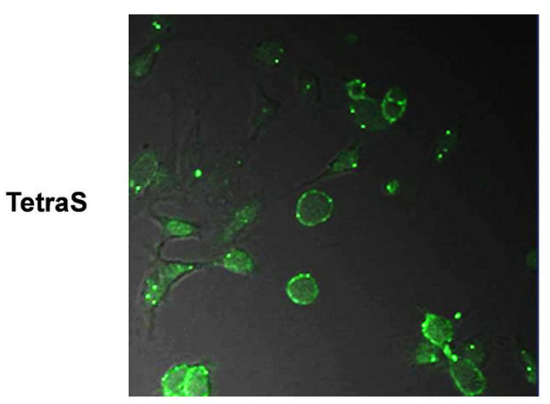

HER2 overexpressing SK-OV 3 cells

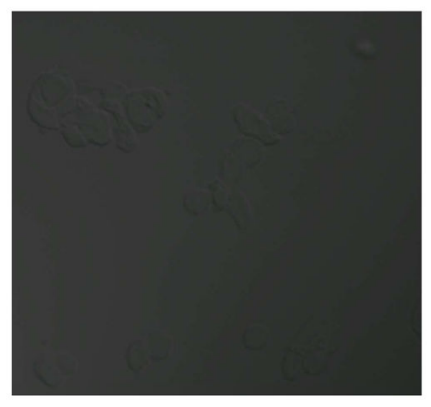

MCF7 cells 


\section{Figure 2C}

Monos
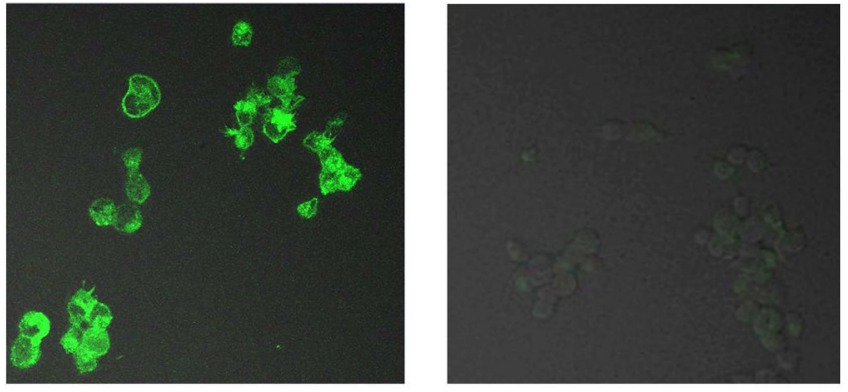

TetraS

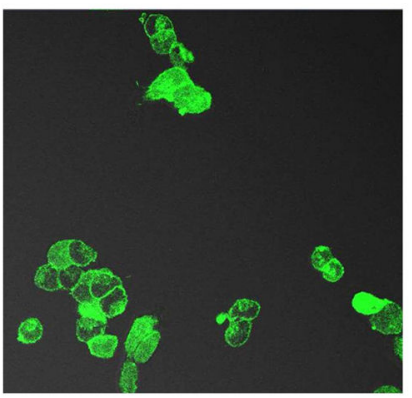

$293^{\text {VEGFR2 }}$ cells

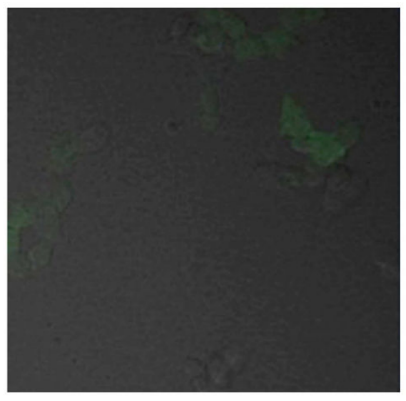

293 cells 
Figure 2D
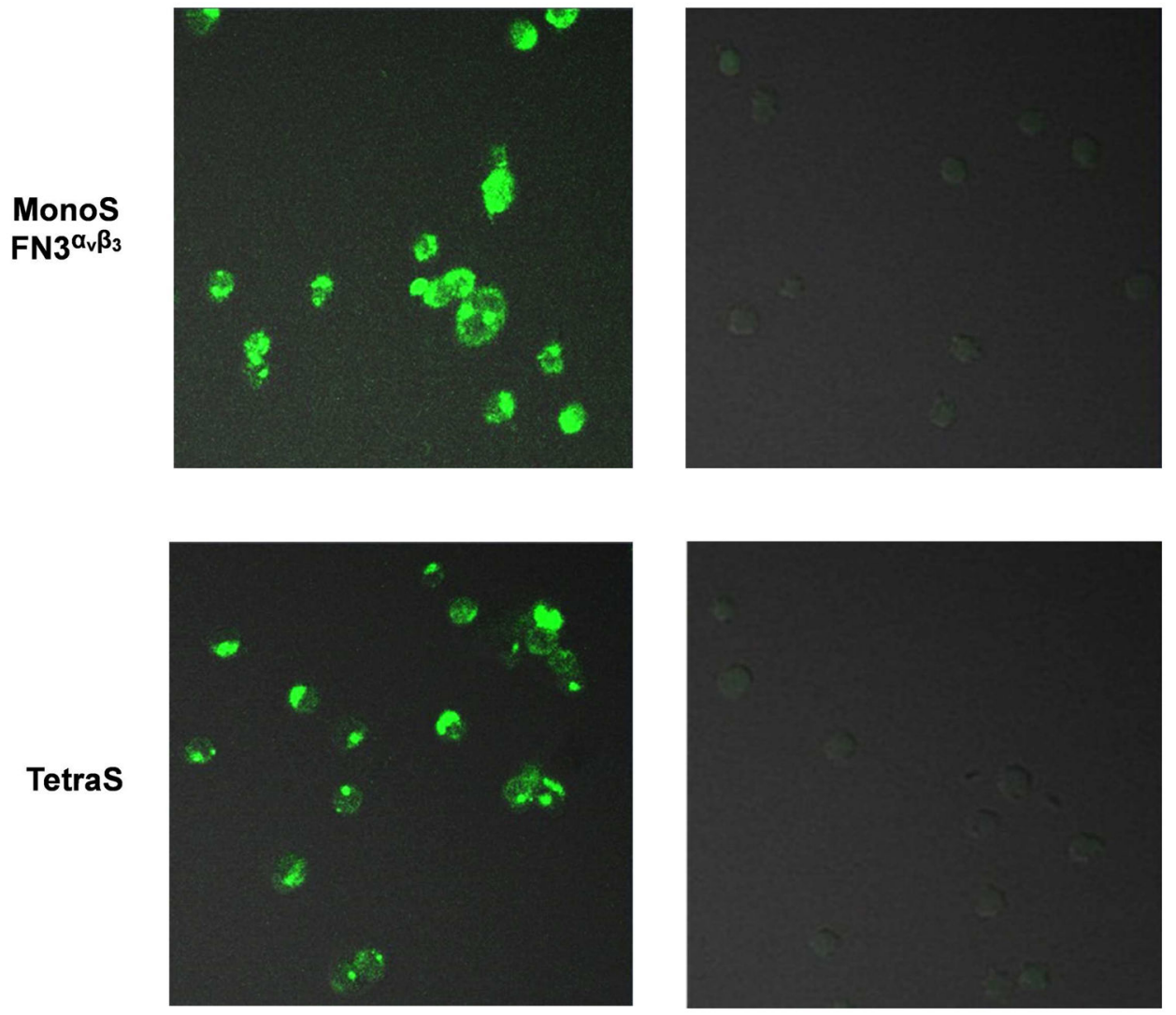

$\mathrm{K}_{562^{\mathrm{a}_{\mathrm{v}} \beta_{3}} \text { cells }}$

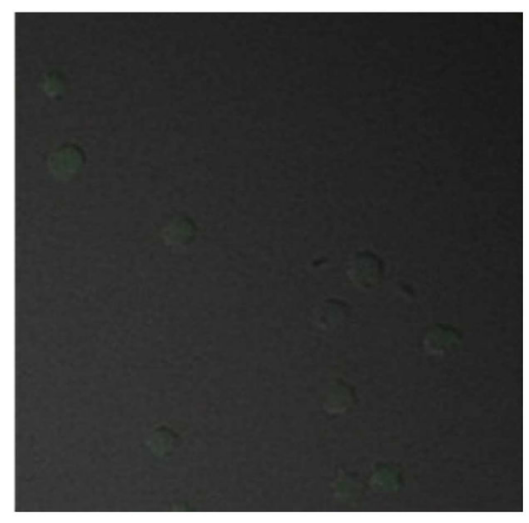

K562 cells

Figure 2. Comparison of the Binding of Monospecific and Tetraspecific Targeting Ligands with Cancer Cells Overexpressing EGFR, HER2, $\alpha_{v} \beta_{3}$ and VEGFR2, Respectively

A) Binding of FITC-labeled monospecific $Z^{\mathrm{EGFR}}$ or tetraspecific ligand with EGFR-positive A431 cells and EGFR-low MCF7 cells.

B) Binding of FITC-labeled monospecific $\mathrm{Z}^{\mathrm{HER} 2}$ or tetraspecific ligand with HER2-positive SK-OV3 cells and HER2-low MCF7 cells.

C) Binding of FITC-labeled monospecific FN3VEGFR2 or tetraspecific ligand with VEGFR2-positive $293^{\text {VEGFR2 }}$ cells and VEGFR2-negative wild type 293 cells.

D) Binding of FITC-labeled monospecific FN $3^{a_{v}} \beta_{3}$ or tetraspecific ligand with $\alpha_{v} \beta_{3}$-positive K562 ${ }^{\alpha_{v}} \beta 3$ cells and $\alpha_{v} \beta_{3}$-negative wild type K562 cells. All the cell-binding signals were visualized by confocal microscopy. 


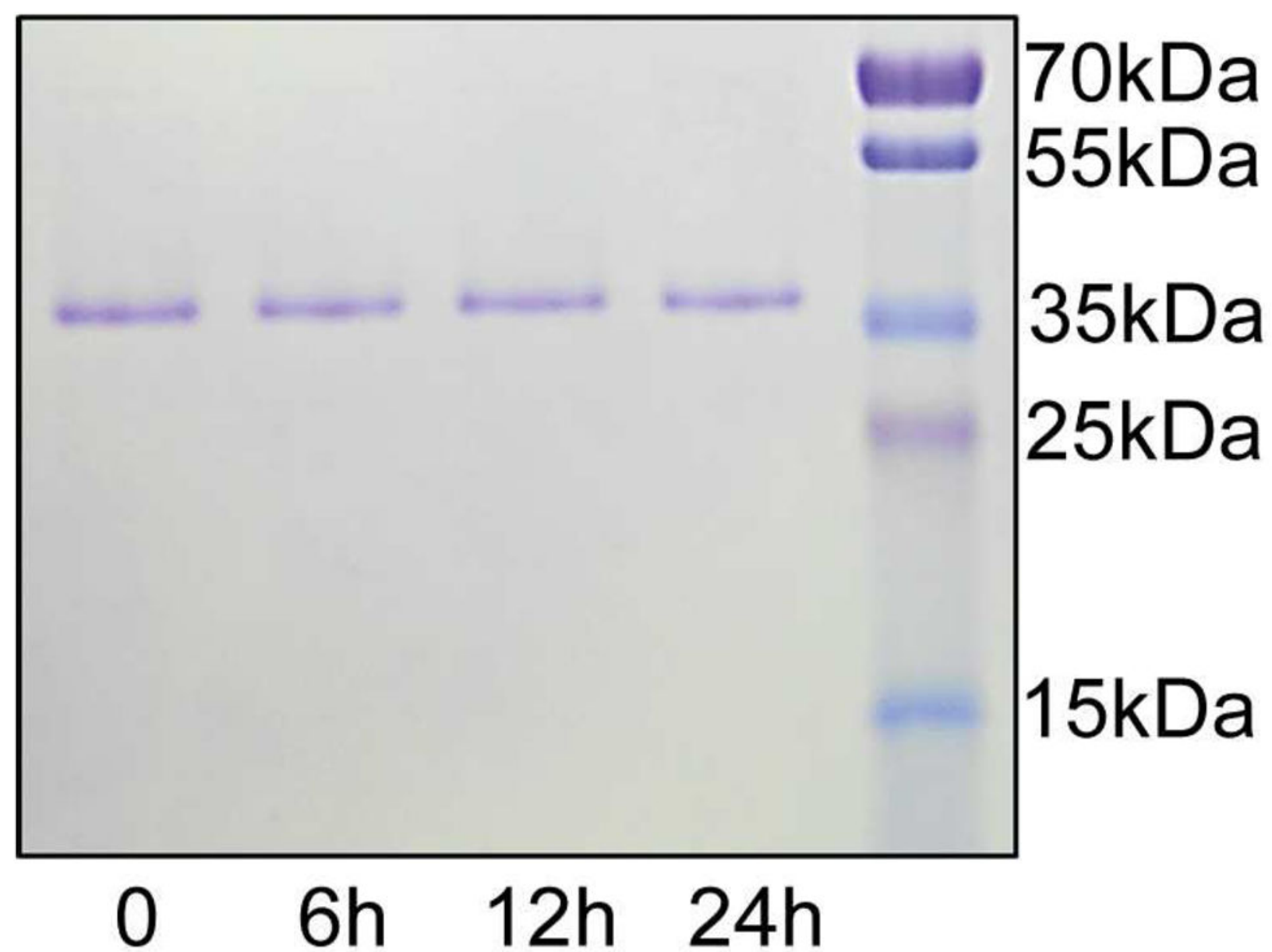

Figure 3. Serum Stability of the Tetraspecific Ligand

Purified tetraspecific ligand $(5 \mu \mathrm{g})$ was incubated with $10 \%$ mouse serum $(5 \mathrm{mg})$ for 0,6 , 12 , and $24 \mathrm{~h}$, respectively. After incubation, the undigested ligand was recovered with $\mathrm{Co}^{2+}$ NTA resin. Each elution product was loaded and the amount quantified on $12 \%$ SDS-PAGE. 
Figure 4A
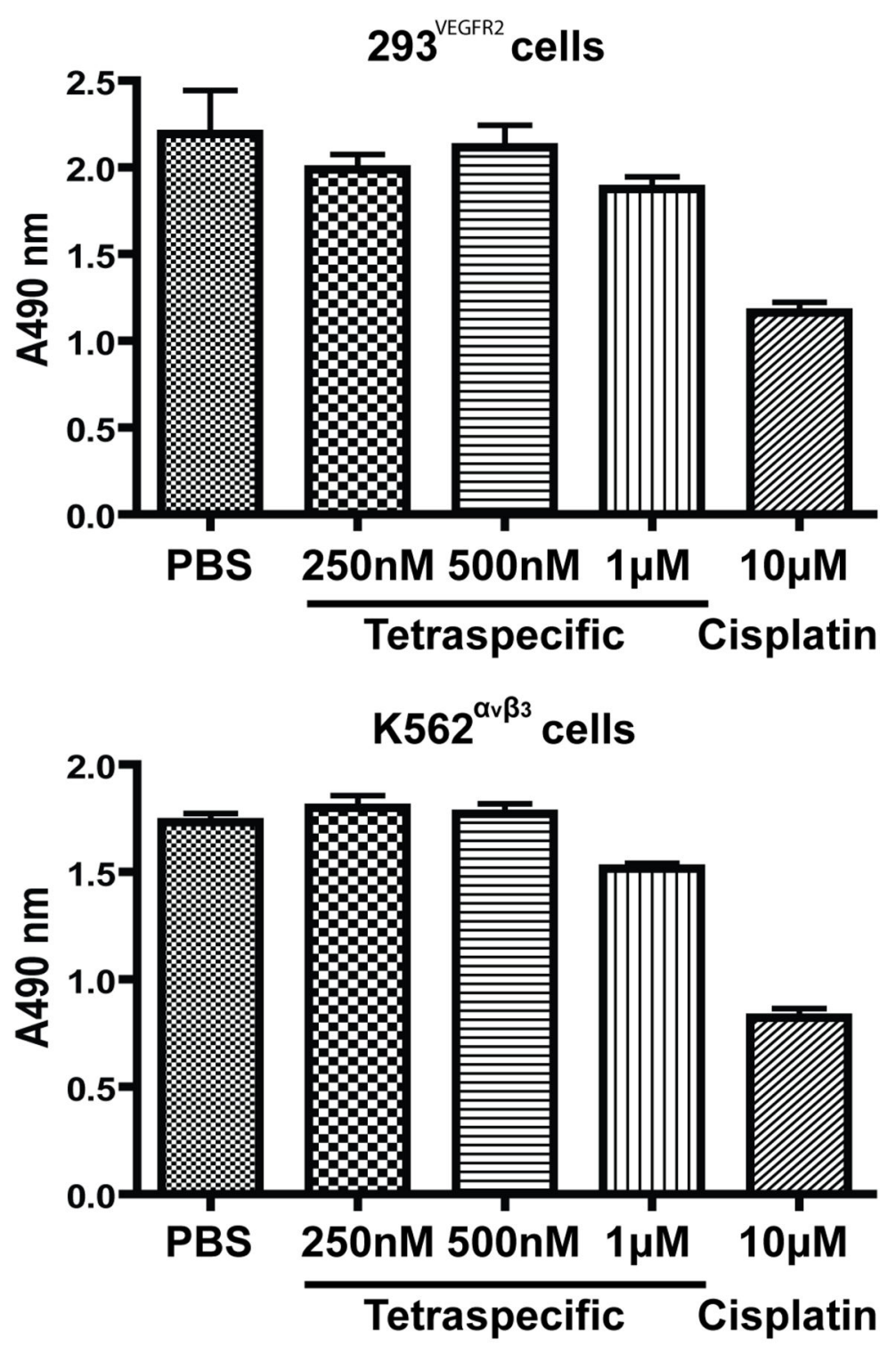


\section{Figure 4B}

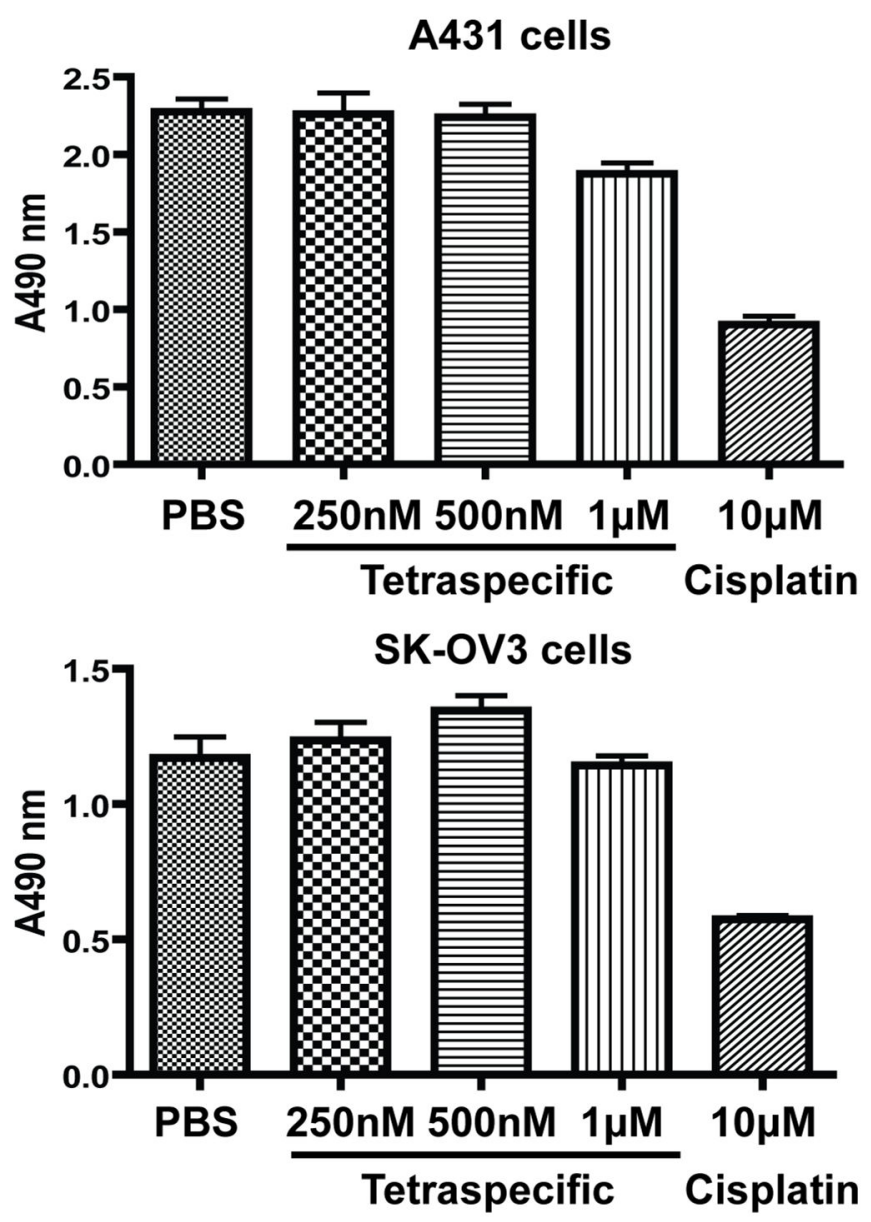

Figure 4. Cell Proliferation Assay

$293^{\text {VEGFR2 }}$, K562 ${ }^{\alpha_{\mathrm{v}} \beta 3}$, A431, and SK-OV3 cells were incubated with various concentrations of tetraspecific ligand for $48 \mathrm{~h}$ at $37^{\circ} \mathrm{C}$. Cisplatin $(10 \mu \mathrm{M})$ was used as a positive control. Cell proliferation was compared based on the absorbance at $490 \mathrm{~nm}$ (A490). 


\section{Figure 5A}
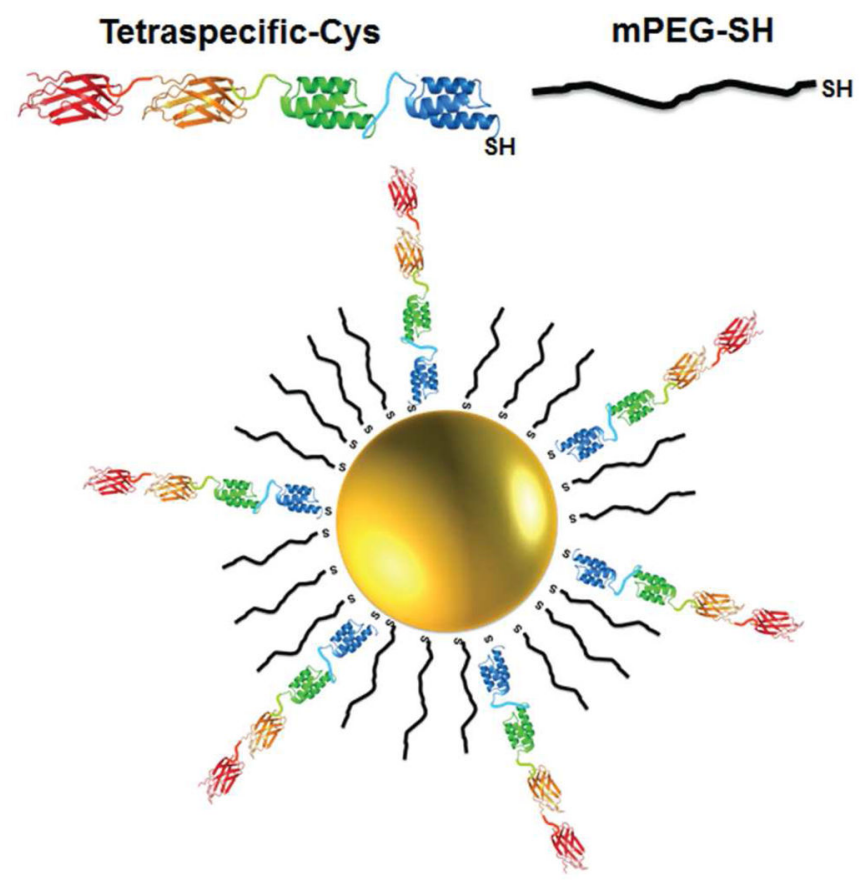

Figure 5B
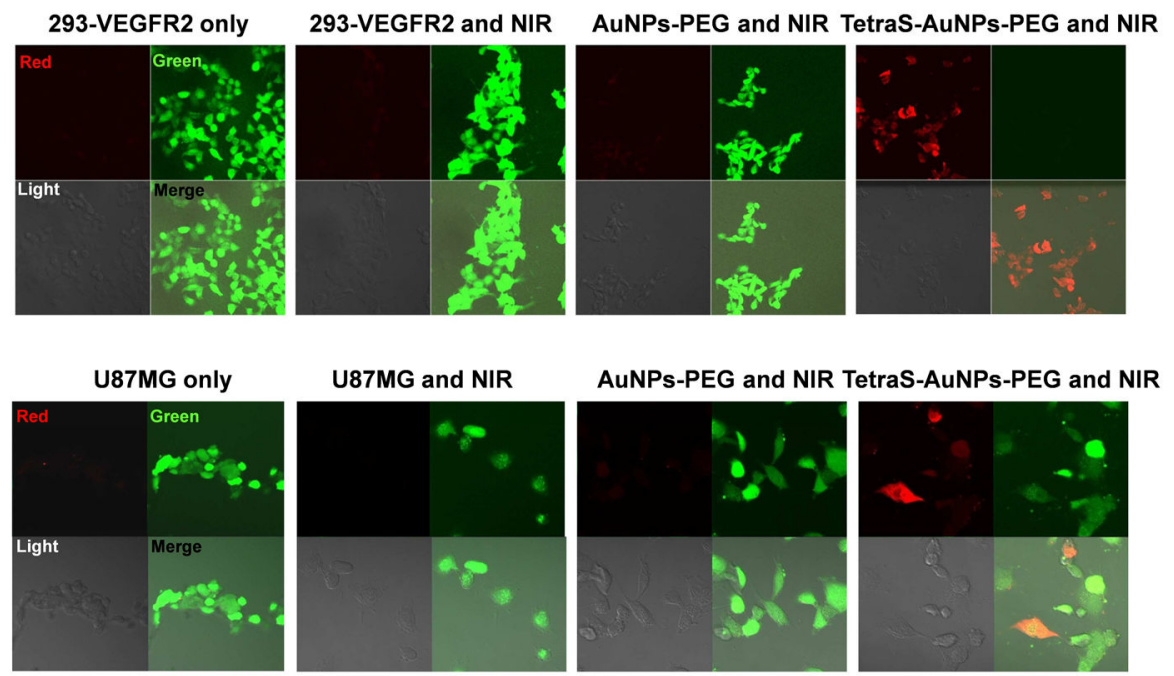

Biomaterials. Author manuscript; available in PMC 2015 July 01. 


\section{Figure 5C}

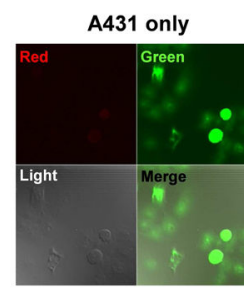

SK-OV3 only

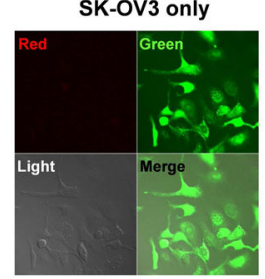

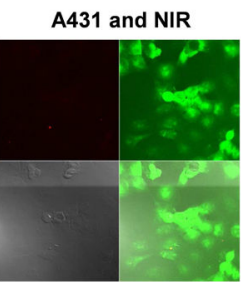

SK-OV3 and NIR

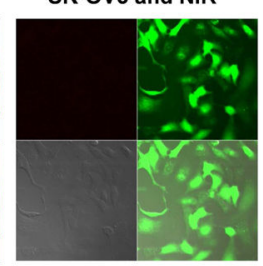

AuNPs-PEG and NIR TetraS-AuNPs-PEG and NIR
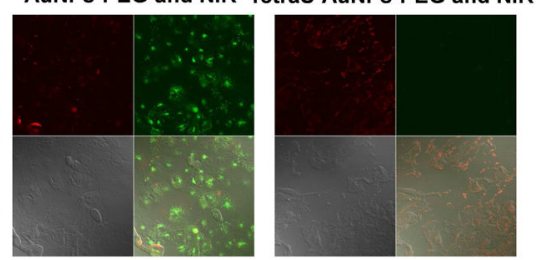

AuNPs-PEG and NIR TetraS-AuNPs-PEG and NIR
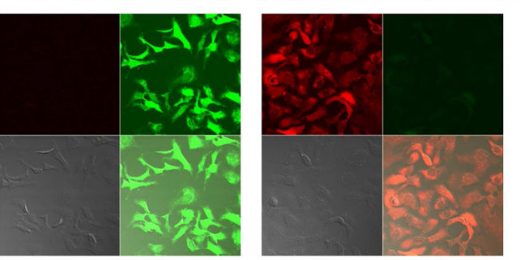

Figure 5. Hyperthermia Treatment of Cancer Cells Using TetraS-AuNP Biomaterial A) Schematic diagram of AuNPs conjugated with tetraspecific ligand and 2 kDa mPEGthiol.

B) and C) The samples (controls or $100 \mathrm{nM}$ of tetraS-AuNP biomaterial) were incubated with each cell line for $30 \mathrm{~min}$ to promote internalization. NIR irradiation ( $800 \mathrm{~nm}, 1$ watt) was performed for $20 \mathrm{~min}$. Calcein AM staining (green fluorescent signal, $1 \mu \mathrm{M}$ ) was used to detect and visualize live cells, and ethidium homodimer-1 (red fluorescent signal, $2 \mu \mathrm{M}$ ) was used to detect and visualize dead cells. 


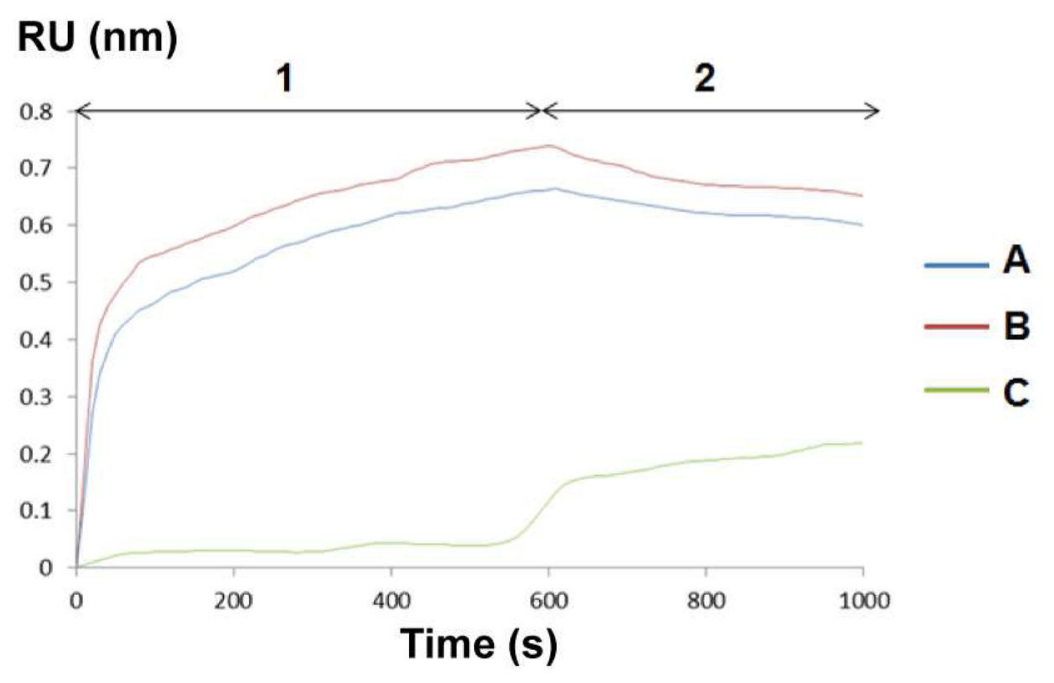

\begin{tabular}{|c|c|c|}
\hline & 1 & 2 \\
\hline A & Tetras & Buffer \\
\hline B & Tetras & Monos-Z $^{\text {EGFR }}$ and MonoS-Z \\
\hline C & Buffer & MonoS-Z $^{\text {EGFR }}$ and MonoS-Z \\
\hline
\end{tabular}

Figure 6. Target-binding Analysis of TetraS-AuNP Bioconjugate Using BLI Octet $0.5 \mu \mathrm{g}$ of EGFR ECD-Fc and HER2 ECD-Fc receptors were loaded on anti-Fc biosensors. A) $200 \mathrm{nM}$ tetraspecific ligand was used for binding with receptors followed by dissociation in the assay buffer (1× PBS, $0.002 \%$ Tween 20, pH 7.4). B) $200 \mathrm{nM}$ tetraspecific ligand was used for binding with receptors followed by competition with a mixture of $200 \mathrm{nM}$ both $\mathrm{Z}^{\mathrm{EGFR}}$ and $\mathrm{Z}^{\mathrm{HER} 2}$ monospecific ligands. C) Biosensor was incubated with assay buffer first followed by incubating with a mixture of $200 \mathrm{nM}$ both $\mathrm{Z}^{\mathrm{EGFR}}$ and $\mathrm{Z}^{\mathrm{HER} 2}$ monospecific ligands. 


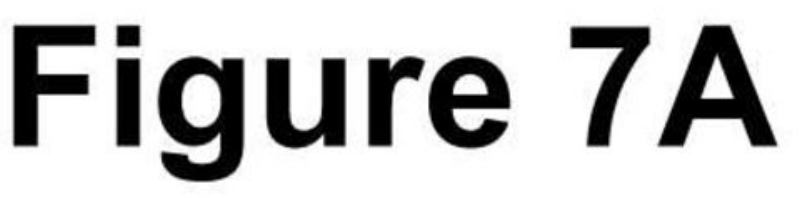

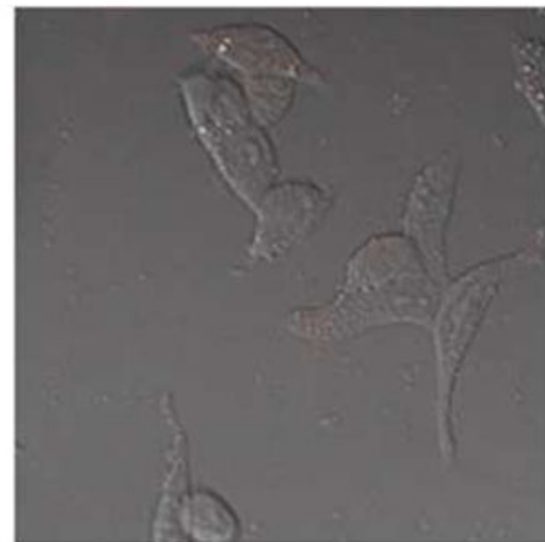

Cell only

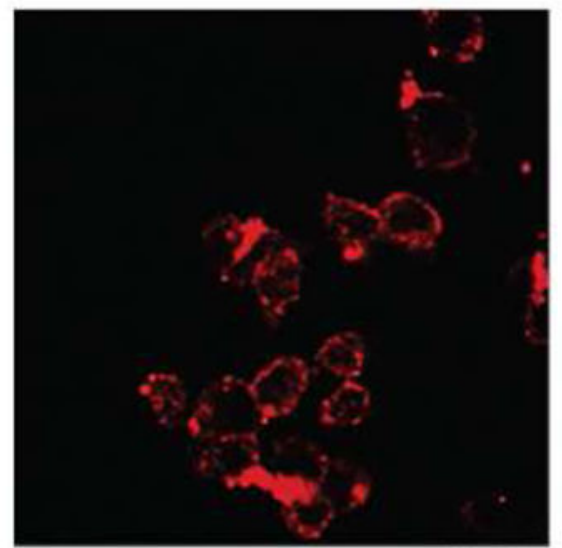

200 nM MonoS $z^{\text {HER2 }}$

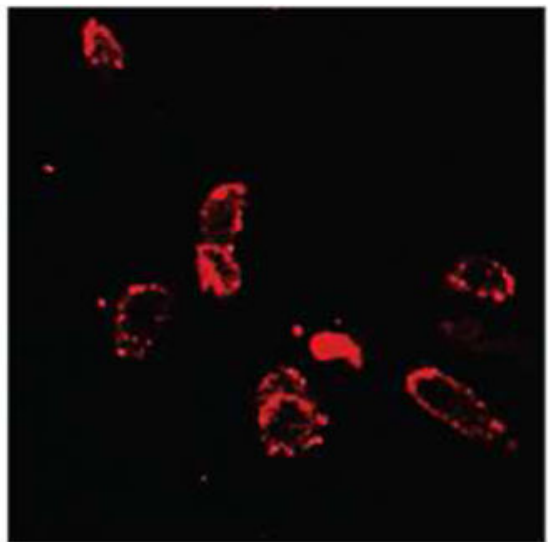

$200 \mathrm{nM}$ Monos $\mathrm{Z}^{\mathrm{EGFR}}$

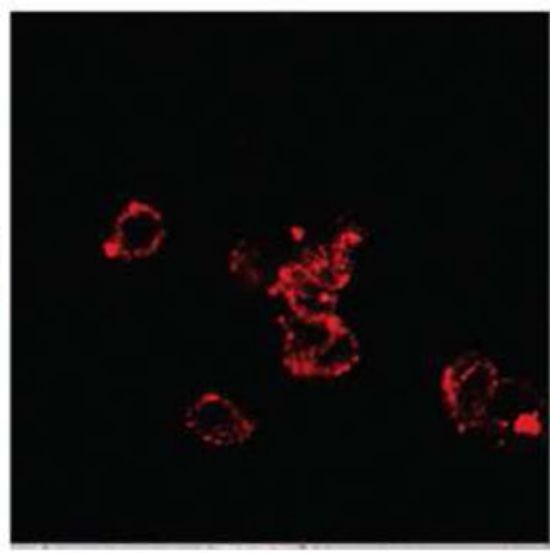

200 nM TetraS 


\section{Figure 7}

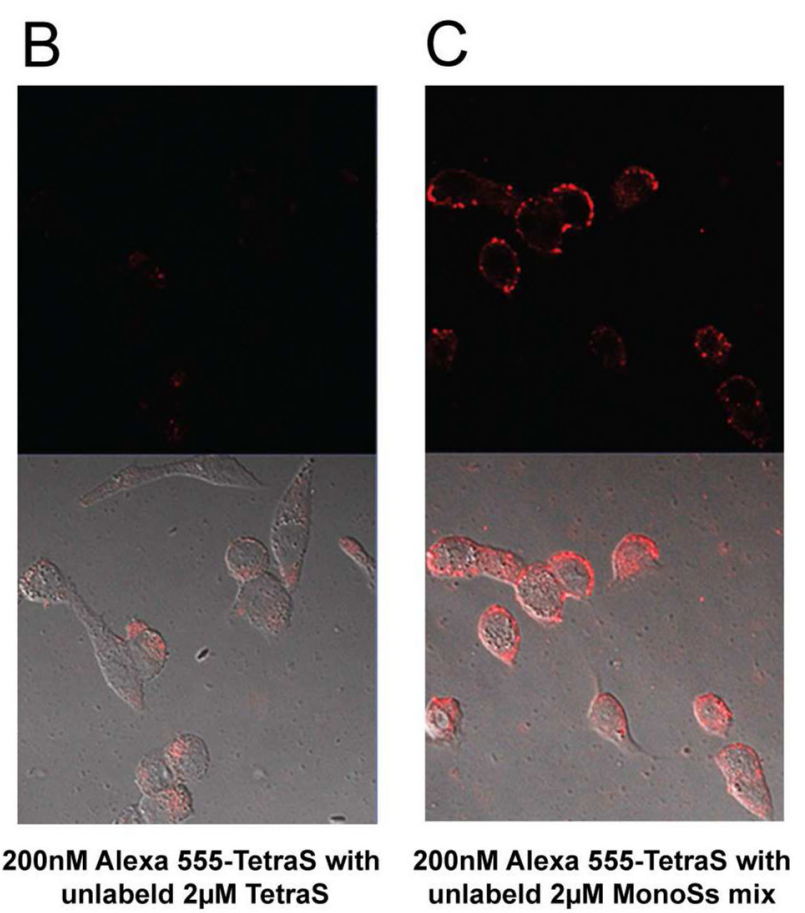

Figure 7. Competition Study between Monospecific and Tetraspecific Ligands with Targets on Cancer Cell Surfaces

A) $200 \mathrm{nM}$ Alexa 555-labeled monospecific $Z^{\mathrm{EGFR}}$, monospecific $\mathrm{Z}^{\mathrm{HER} 2}$, and tetraspecific ligand were incubated with LNCaP cells for $30 \mathrm{~min}$ at $25^{\circ} \mathrm{C}$. The cell-binding signals were visualized by confocal microscopy.

B) $200 \mathrm{nM}$ Alexa 555-labeled tetraspecific ligand was mixed with 10 molar excess $(2 \mu \mathrm{M})$ of unlabeled tetraspecific ligand, followed by incubation with LNCaP cells for $30 \mathrm{~min}$ at 25 ${ }^{\circ} \mathrm{C}$.

C) $200 \mathrm{nM}$ Alexa 555-labeled tetraspecific ligand was mixed with a mixture of 10 molar excess $(2 \mu \mathrm{M})$ of unlabeled monospecific $\mathrm{Z}^{\mathrm{EGFR}}$ and $\mathrm{Z}^{\mathrm{HER} 2}$ ligands, followed by incubation with LNCaP cells for $30 \mathrm{~min}$ at $25^{\circ} \mathrm{C}$. The cell-binding signals were visualized by confocal microscopy. 


\section{Table 1}

SPR Binding Analysis of Each Monospecific and Tetraspecific Targeting Ligand Using Purified Receptors

\begin{tabular}{|c|c|c|c|}
\hline \multirow{2}{*}{ Targeting ligand } & \multicolumn{3}{|c|}{ Target receptor: VEGFR2 } \\
\cline { 2 - 4 } & $\mathbf{k}_{\mathbf{a}}\left(\mathbf{M}^{-\mathbf{1}} \mathbf{s}^{-\mathbf{1}}\right)$ & $\mathbf{k}_{\mathbf{d}}\left(\mathbf{s}^{\mathbf{- 1}}\right)$ & $\mathbf{K}_{\mathbf{D}}(\mathbf{M})$ \\
\hline MonoS FN3 $^{\text {VEGFR2 }}$ & $1.0 \pm 0.2 \times 10^{3}$ & $4.9 \pm 0.5 \times 10^{-7}$ & $0.5 \pm 0.1 \times 10^{-9}$ \\
\hline TetraS & $1.0 \pm 0.4 \times 10^{3}$ & $1.4 \pm 0.4 \times 10^{-6}$ & $1.4 \pm 0.2 \times 10^{-9}$ \\
\hline
\end{tabular}

\begin{tabular}{|c|c|c|c|}
\hline \multirow{2}{*}{ Targeting ligand } & \multicolumn{3}{|c|}{ Target receptor: $\alpha_{\mathbf{v}} \beta_{\mathbf{3}}$} \\
\cline { 2 - 4 } & $\mathbf{k}_{\mathbf{a}}\left(\mathbf{M}^{-\mathbf{1}} \mathbf{s}^{-\mathbf{1}}\right)$ & $\mathbf{k}_{\mathbf{d}}\left(\mathbf{s}^{\mathbf{- 1}}\right)$ & $\mathbf{K}_{\mathbf{D}}(\mathbf{M})$ \\
\hline MonoS FN3 $^{\mathrm{a}_{\mathrm{v}} \beta_{3}}$ & $2.5 \pm 0.2 \times 10^{3}$ & $8.0 \pm 0.4 \times 10^{-6}$ & $31 \pm 3.0 \times 10^{-9}$ \\
\hline TetraS & $\underline{1.1 \pm 0.2 \times 10^{3}}$ & $8.0 \pm 0.6 \times 10^{-6}$ & $73 \pm 5.5 \times 10^{-9}$ \\
\hline
\end{tabular}

\begin{tabular}{|c|c|c|c|}
\hline \multirow[t]{2}{*}{ Targeting ligand } & \multicolumn{3}{|c|}{ Target receptor: EGFR } \\
\hline & $k_{a}\left(M^{-1} s^{-1}\right)$ & $\mathbf{k}_{\mathrm{d}}\left(\mathrm{s}^{-\mathbf{1}}\right)$ & $\mathbf{K}_{\mathbf{D}}(\mathbf{M})$ \\
\hline MonoS Z ZGFR & $1.0 \pm 0.2 \times 10^{3}$ & $2.6 \pm 0.3 \times 10^{-7}$ & $2.6 \pm 0.3 \times 10^{-9}$ \\
\hline TetraS & $3.1 \pm 0.6 \times 10^{3}$ & $5.2 \pm 1.2 \times 10^{-6}$ & $17 \pm 3.4 \times 10^{-9}$ \\
\hline
\end{tabular}

\begin{tabular}{|c|c|c|c|}
\hline \multirow{2}{*}{ Targeting ligand } & \multicolumn{3}{|c|}{ Target receptor: HER2 } \\
\cline { 2 - 4 } & $\mathbf{k}_{\mathbf{a}}\left(\mathbf{M}^{\mathbf{- 1}} \mathbf{s}^{\mathbf{- 1}}\right)$ & $\mathbf{k}_{\mathbf{d}}\left(\mathbf{s}^{\mathbf{- 1}}\right)$ & $\mathbf{K}_{\mathbf{D}}(\mathbf{M})$ \\
\hline MonoS Z HER2 & $0.9 \pm 0.2 \times 10^{3}$ & $7.7 \pm 1.5 \times 10^{-7}$ & $0.9 \pm 0.2 \times 10^{-9}$ \\
\hline TetraS & $4.4 \pm 1.3 \times 10^{3}$ & $6.4 \pm 2.1 \times 10^{-6}$ & $15 \pm 5.1 \times 10^{-9}$ \\
\hline
\end{tabular}


Table 2

Cell-binding Affinity Measurement by Flow Cytometry

\begin{tabular}{|c|c|c|c|c|}
\hline Cell lines & Targeting ligand & $\mathbf{K}_{\mathbf{D}}$ & Targeting ligand & $\mathbf{K}_{\mathbf{D}}$ \\
\hline A431 & MonoS Z ${ }^{\text {EGFR }}$ & $11 \pm 1 \mathrm{nM}$ & TetraS & $28 \pm 3 \mathrm{nM}$ \\
\hline SK-OV3 & MonoS Z ${ }^{\text {HER2 }}$ & $10 \pm 2 \mathrm{nM}$ & TetraS & $25 \pm 2 \mathrm{nM}$ \\
\hline $2^{293^{\text {VEGFR2 }}}$ & MonoS FN3 ${ }^{\text {VEGFR2 }}$ & $110 \pm 11 \mathrm{nM}$ & TetraS & $160 \pm 12 \mathrm{nM}$ \\
\hline K562 $^{a_{\mathrm{v}} \beta_{3}}$ & MonoS FN3 $^{\mathrm{a}_{\mathrm{\beta}} 3}$ & $120 \pm 8 \mathrm{nM}$ & TetraS & $145 \pm 8 \mathrm{nM}$ \\
\hline
\end{tabular}


Table 3

The Melting Temperatures of Monospecific and Tetraspecific Targeting Ligands Estimated by CD Analysis

\begin{tabular}{|c|c|}
\hline Targeting ligand & $\mathbf{T}_{\mathbf{m}}\left({ }^{\circ} \mathbf{C}\right)$ \\
\hline MonoS-FN3 $^{\text {VEGFR2 }}$ & $61.5 \pm 0.5$ \\
\hline MonoS-FN3 $^{\mathrm{a}_{\mathrm{v}} 33}$ & $80.0 \pm 2.0$ \\
\hline MonoS-Z $^{\text {EGFR }}$ & $61.0 \pm 1.0$ \\
\hline MonoS-Z $^{\mathrm{HER} 2}$ & $63.5 \pm 1.5$ \\
\hline TetraS & $60.0 \pm 2.0$ \\
\hline
\end{tabular}




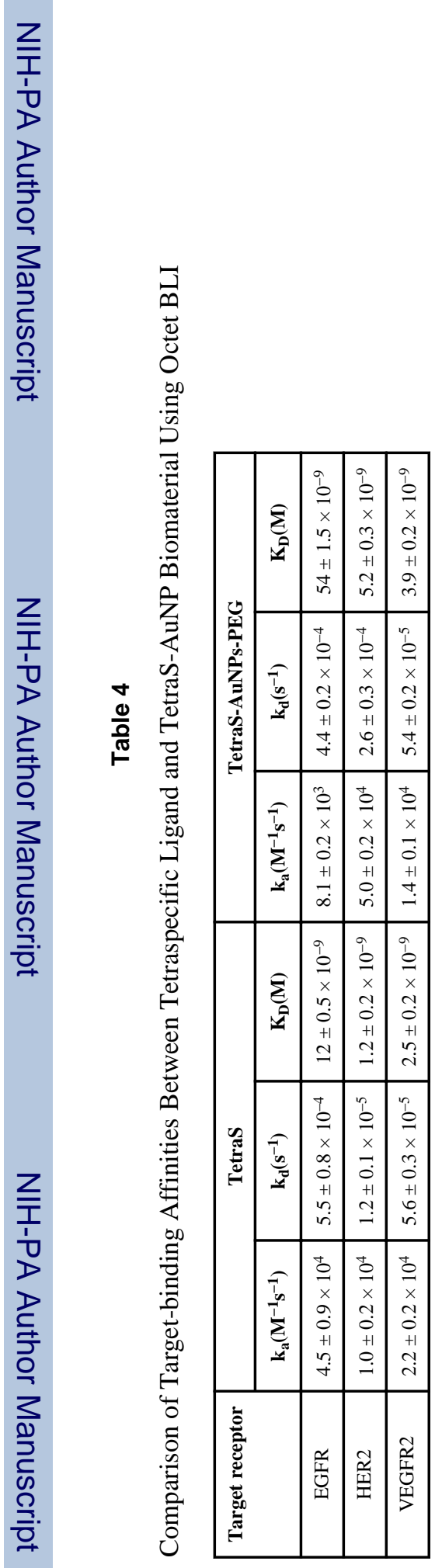

Biomaterials. Author manuscript; available in PMC 2015 July 01. 
Table 5

$\mathrm{K}_{\mathrm{D}}$ Measurements of Tetraspecific Ligand on Different Receptor(s) by Octet

\begin{tabular}{|c|c|}
\hline Molar ratio of immobilized receptor(s) & $\mathbf{K}_{\mathbf{D}}$ \\
\hline$[$ EGFR] $:[\mathrm{HER} 2]=1: 0$ & $8.4 \mathrm{nM}$ \\
\hline$[$ EGFR] $:[\mathrm{HER} 2]=0: 1$ & $1.3 \mathrm{nM}$ \\
\hline$[$ EGFR] $:[\mathrm{HER} 2]=1: 1$ & $0.75 \mathrm{pM}$ \\
\hline$[$ EGFR] $:[\mathrm{HER} 3]=1: 1$ & $9.0 \mathrm{nM}$ \\
\hline$[\mathrm{HER} 2]:[\mathrm{HER} 3]=1: 1$ & $1.0 \mathrm{nM}$ \\
\hline
\end{tabular}

